\title{
THE PEOPLE'S REPUBLIC OF CHINA'S POTENTIAL GROWTH RATE: THE LONG- RUN CONSTRAINTS
}

Jesus Felipe, Matteo Lanzafame, and Juzhong Zhuang

No.418 ADB ECONOMICS

November 2014

\section{WORKING PAPER SERIES}


ADB Economics Working Paper Series

\section{The People's Republic of China's Potential Growth Rate: The Long-Run Constraints}

Jesus Felipe, Matteo Lanzafame, and Juzhong Zhuang

\begin{tabular}{l|l} 
No. 418 | 2014
\end{tabular}
Jesus Felipe (jfelipe@adb.org) is Advisor in the Economics and Research Department (ERD) of the Asian Development Bank (ADB). Matteo Lanzafame (mlanzafame@unime.it) is Assistant Professor in the Department of Economics, Management, Environmental and Quantitative Methods (SEAM, Università degli Studi di Messina, Italy. Juzhong Zhuang (jzhuang@adb.org) is Deputy Chief Economist in ERD, ADB.

We are grateful to Corina Bautista, Carsten Holz, Yolanda Fernandez-Lommen, Kaukab Naqvi, and Tom Rawski for comments and suggestions. 
Asian Development Bank

6 ADB Avenue, Mandaluyong City

1550 Metro Manila, Philippines

www.adb.org

(C) 2014 by Asian Development Bank

November 2014

ISSN 2313-6537 (Print), 2313-6545 (e-ISSN)

Publication Stock No. WPS147000-3

The views expressed in this paper are those of the author and do not necessarily reflect the views and policies of the Asian Development Bank (ADB) or its Board of Governors or the governments they represent.

ADB does not guarantee the accuracy of the data included in this publication and accepts no responsibility for any consequence of their use.

By making any designation of or reference to a particular territory or geographic area, or by using the term "country" in this document, $A D B$ does not intend to make any judgments as to the legal or other status of any territory or area.

Notes:

In this publication, "\$" refers to US dollars.

The ADB Economics Working Paper Series is a forum for stimulating discussion and eliciting feedback on ongoing and recently completed research and policy studies undertaken by the Asian Development Bank (ADB) staff, consultants, or resource persons. The series deals with key economic and development problems, particularly those facing the Asia and Pacific region; as well as conceptual, analytical, or methodological issues relating to project/program economic analysis, and statistical data and measurement. The series aims to enhance the knowledge on Asia's development and policy challenges; strengthen analytical rigor and quality of ADB's country partnership strategies, and its subregional and country operations; and improve the quality and availability of statistical data and development indicators for monitoring development effectiveness.

The ADB Economics Working Paper Series is a quick-disseminating, informal publication whose titles could subsequently be revised for publication as articles in professional journals or chapters in books. The series is maintained by the Economics and Research Department. 


\section{CONTENTS}

TABLES AND FIGURES

ABSTRACT $\quad v$

EXECUTIVE SUMMARY Vi

$\begin{array}{lll}\text { I. INTRODUCTION } & 1\end{array}$

II. THE 18TH NATIONAL CONGRESS OF THE CHINESE COMMUNIST PARTY
AND THE 13TH FIVE-YEAR PLAN

III. ACTUAL, NATURAL, AND BALANCE OF PAYMENTS CONSTRAINED GROWTH RATES

IV. ESTIMATES OF THE PEOPLE'S REPUBLIC OF CHINA'S NATURAL AND BALANCE OF PAYMENTS CONSTRAINED GROWTH RATES

V. SCENARIOS FOR THE PEOPLE'S REPUBLIC OF CHINA'S POTENTIAL GROWTH DURING THE 13TH FIVE-YEAR PLAN, 2016-2020

VI. CONCLUSIONS: THE PEOPLE'S REPUBLIC OF CHINA'S POTENTIAL GROWTH PROSPECTS DURING THE 13TH FIVE-YEAR PLAN AND IMPLICATIONS FOR POLICY

$\begin{array}{ll}\text { APPENDIX } & 23\end{array}$

$\begin{array}{ll}\text { REFERENCES } & 33\end{array}$ 


\section{TABLES AND FIGURES}

\section{TABLES}

1 Summary of Estimates of the Determinants of Natural and Balance of Payments Constrained Growth Rates

2 Scenarios for the Path of the People's Republic of China's Natural Growth Rate, 2016-2020

\section{FIGURES}

$1 \quad$ Actual and Trend Growth Rates

2 Gross Domestic Product per Capita and Time Elapsed After Reaching $\$ 3,000$

3 Sectors' Employment Shares

4 Actual, Natural, and Balance of Payments Constrained Growth Rates

$5 \quad$ Change in the People's Republic of China's Inflation Rate

6 The People's Republic of China's Natural Growth Rate: Actual and Predicted Values 


\begin{abstract}
We estimate the People's Republic of China's (PRC's) potential growth rate in 2012 at $8.7 \%$ and at 9.2\% for the average of 2008-2012, about the same as the average actual growth rate for this period. This rate is the natural growth rate, that is, the rate consistent with a constant unemployment rate and stable inflation. The PRC's natural growth rate displays a downward trend since 2006, when it peaked at $11.1 \%$. Probably the Great Recession has been an important factor, although we argue that there are other factors. We show that the PRC's potential growth rate is not demand constrained, in particular by the balance of payments. The PRC's potential growth rate is determined by the supply side of the economy, in particular by: (i) changes in the structure of the economy, in particular in the share of industrial employment; (ii) the working-age population; (iii) the share of net exports in gross domestic product (GDP); (iv) export growth; (v) the share of foreign direct investment (FDI) in GDP; and (vi) human capital accumulation.
\end{abstract}

Keywords: balance of payments constrained growth rate, Kalman filter, natural growth rate, Okun's Law, People's Republic of China, potential growth rate

JEL Classification: $014,047,053$ 


\section{EXECUTIVE SUMMARY}

The Chinese Communist Party set an ambitious reform agenda for the 12th Five-Year Plan (20112015). These reforms are expected to continue during the 13th Five-Year Plan (2016-2020). There is agreement that the People's Republic of China (PRC) needs to change its growth model into one that is less capital and energy-intensive, and less dependent on credit and real estate booms; yet it needs to continue achieving high growth rates to generate employment and absorb 240 million agricultural workers by industry and services. Policymakers need to evaluate their options, since during the last few years the actual growth rate has declined significantly. Policymakers wonder whether this decline is temporary or permanent, whether the economy's potential has been affected or not, and whether the capacity of the economy to create employment has been affected.

We estimate the PRC's potential growth rate in 2012 at $8.7 \%$ and at $9.2 \%$ for the average of 2008-2012, about the same as the average actual growth rate for this period. This rate is the natural growth rate, that is, the rate consistent with a constant unemployment rate and stable inflation. The PRC's natural growth rate displays a downward trend since 2006 , when it peaked at $11.1 \%$. Probably the Great Recession has been an important factor, although we argue that there are other factors. We show that the PRC's potential growth rate is not demand constrained, in particular by the balance of payments. The PRC's potential growth rate is determined by the supply side of the economy, in particular by: (i) changes in the structure of the economy, in particular in the share of industrial employment; (ii) the working-age population; (iii) the share of net exports in gross domestic product (GDP); (iv) export growth; (v) the share of foreign direct investment (FDI) in GDP; and (vi) human capital accumulation.

We use this framework to discuss three scenarios for the 13th Five-Year Plan (2016-2020), which permit us to put in context a target actual growth rate of about $7 \%$. Under a first scenario, the effects of the Great Recession are temporary and the PRC's potential growth rate returns to over 10\%. This will put upward pressure on unemployment and will call for measures to increase aggregate demand. In the second scenario, the effects of the Great Recession become permanent and the potential growth rate declines to even below the actual growth rate. In such a case, the main consequence is that there will be inflationary pressures. Finally, in the third scenario, the industrial sector loses weight (the economy becomes more services-based) and the potential rate continues declining and approaching the actual rate. This is what we believe is currently happening in the PRC today. That is, it is likely that potential growth rate will decline during the next few years and the challenge for the country's policymakers will be to keep actual and potential growth rates close to each other.

This means that whether an actual growth rate of $7 \%$ is enough to prevent the unemployment rate from increasing (if potential is above actual), or from bringing inflationary pressures into the economy, (if actual is above potential) will depend on two forces: on the one hand, whether the Great Recession has lasting effects on the world and PRC's economies; and on the other hand, how the natural/potential growth rate changes in the coming years as the PRC continues its transformation toward a primarily service-based economy. From a policymaking point of view, our analysis implies that if the authorities are keen to target a growth rate of about $7 \%$ during the 13th Five-Year Plan, then they ought to consider the consequences of an actual growth rate that is significantly different from the country's potential. 
"When we focus on GDP, we are actually focusing on employment... ...We need stable growth in order to create employment"

Premier Li Keqiang. Speech delivered at the 16th National Congress of the All-China Federation of Trade Unions in 2013

\section{INTRODUCTION}

There is growing consensus among economists and analysts of the People's Republic of China (PRC) that, after decades of very fast growth, the country's growth rate and, particularly, its potential growth rate, may be on a downward trajectory (Anand et al. 2014; IMF 2014, Box 10). Figure 1 shows our estimate of the PRC's trend growth rate, confirming its downward trend since the mid-2000s.'

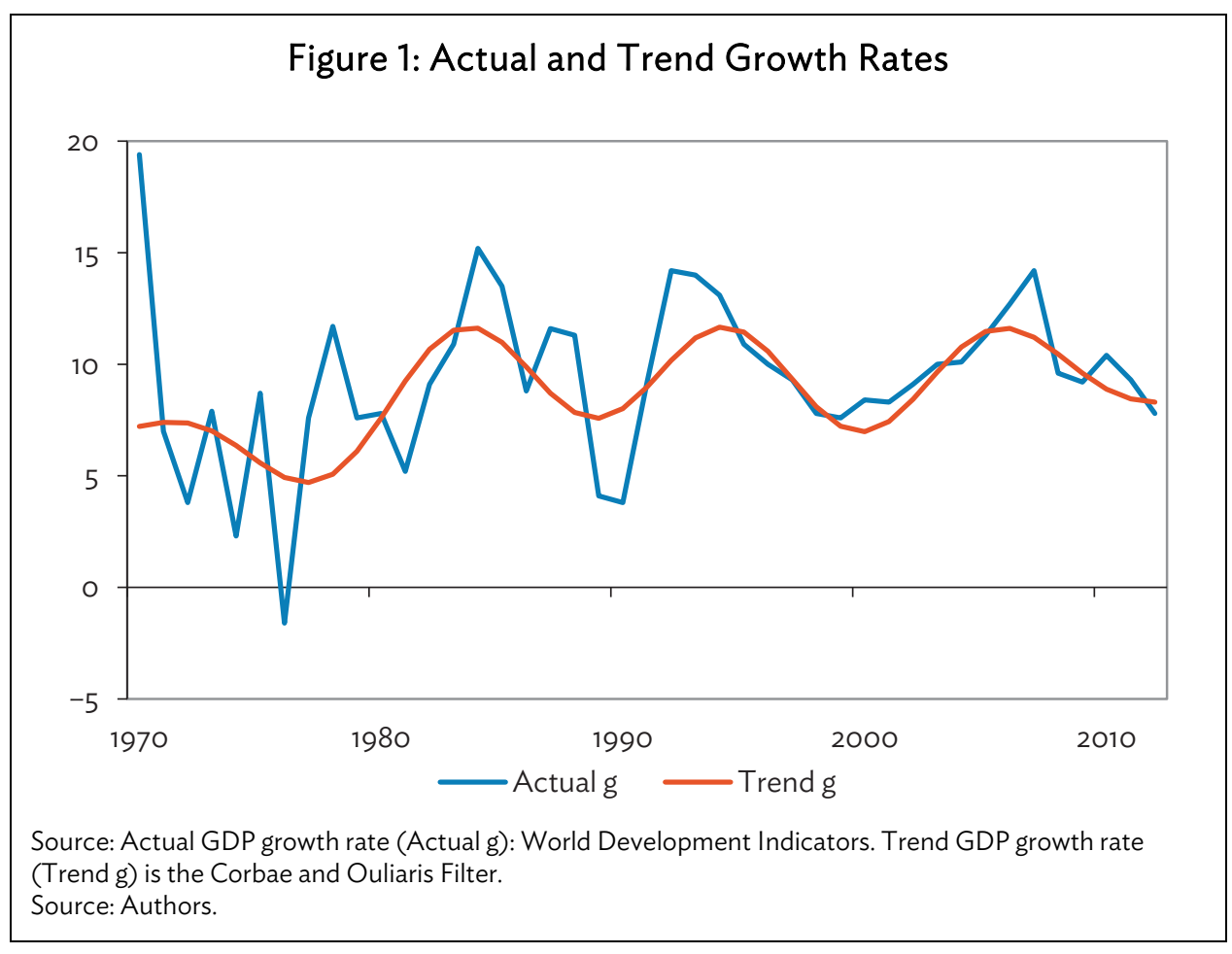

This decline is consistent with the empirical evidence on the relationship between the level of GDP per capita and growth slowdowns, which indicates that the PRC is approaching the per capita GDP threshold after which the likelihood of a permanent growth slowdown becomes significant. For instance, Eichengreen, Park, and Shin (2013) find that growth slowdowns occur at two income

1 To estimate the trend growth rate we rely on the frequency domain filter developed by Corbae, Ouilaris, and Philips (2002), and Corbae and Ouliaris (2006), and apply it to the real GDP series of the PRC. The main advantage of this filter with respect to the available alternatives in the literature is that it can handle both stochastic and deterministic trends, so that the series under analysis can be stationary or (as expected in the case of real GDP) contain a unit root. Exploiting this property, we apply the Corbae-Ouliaris filter to the logarithmic transform of the level of real GDP $\left(\ln Y_{t}\right)$ and obtain a proxy for the trend, $\left(\ln Y_{t}^{T}\right)$. Subsequently, we use $\ln Y_{t}^{T}$ to construct the growth rate of trend real GDP as $g^{T}=\left(\ln Y_{t}^{T}-\ln Y_{t-1}^{T}\right)$. 
thresholds: first, when per capita GDP (measured in purchasing power parity [PPP] terms and $2005 \$$ ) reaches about $\$ 10,000-11,000$; and then when it reaches $\$ 15,000-16,000$. The PRC's per capita GDP is close to $\$ 10,000$ (measured in PPP terms). Figure 2 shows the time elapsed since the PRC and a group of comparator Asian countries reached $\$ 3,000$ in per capita PPP terms. The PRC reached it almost 20 years ago, in 1996, and may be entering the first growth slowdown phase. Also, based on an analysis of growth decelerations, Perkins (2013, pp. 159-163) argues that if the PRC's growth is going to decelerate at approximately the same level as in countries that have achieved high-income status, that time has come.

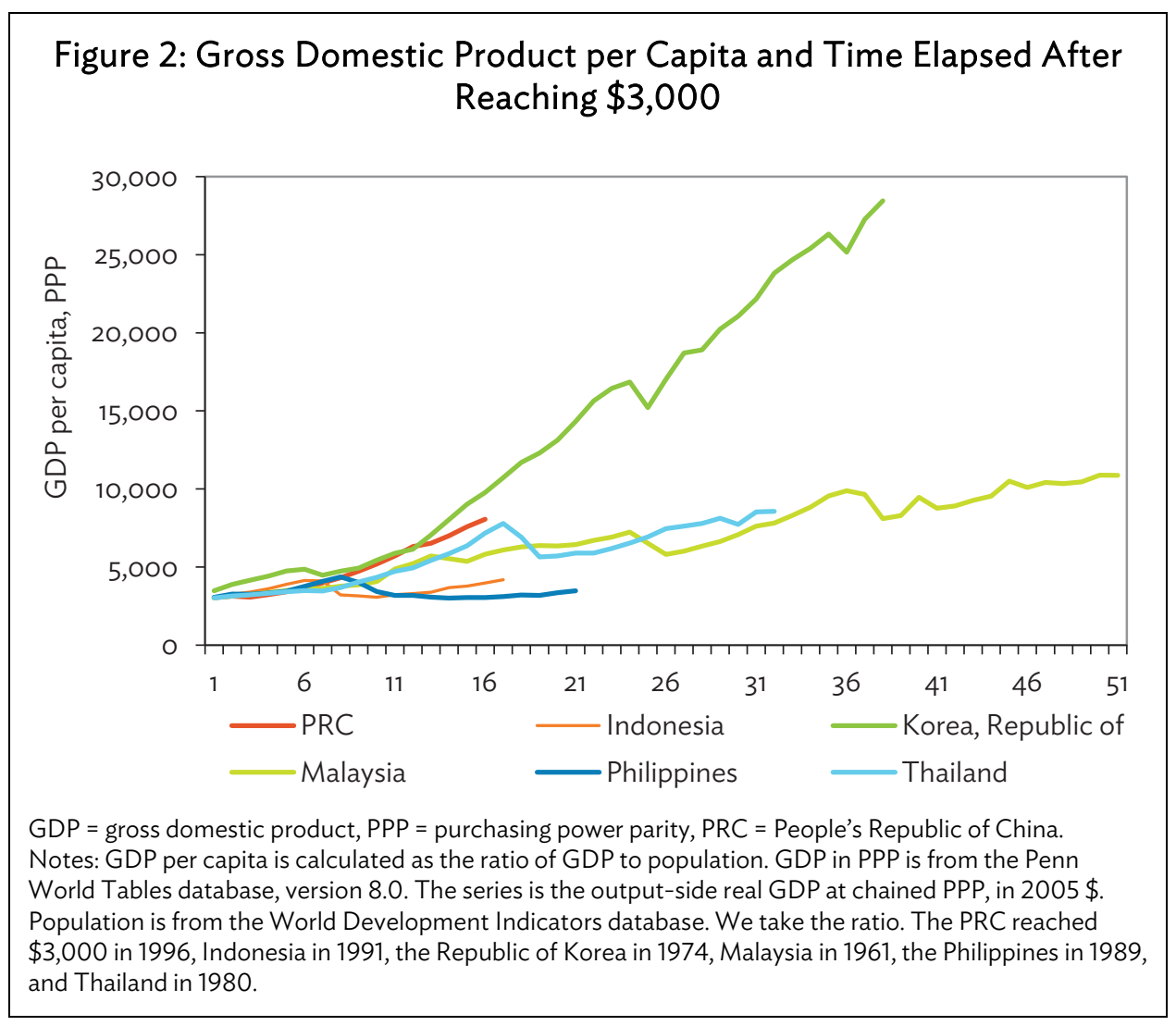

Moreover, a number of factors seem to signal that the recent decrease in the PRC's growth rate may be structural, rather than temporary, in the sense that it reflects a permanent shift to a slower potential growth rate path. Reasons put forward to support this contention range from the exhaustion of gains from a growth process overly reliant on investment and natural resources, to bottlenecks in labor supply which may trigger inflationary pressures, to the need to deal with the significant environmental costs of the current growth strategy. More generally, as argued by Felipe et al. (2013), we can expect that the sustained pace that characterized the PRC's economic transformation during the last 30 years will likely decrease in the coming decades and, as a consequence, so will its growth rate. $^{2}$ In addition to all this, there are also concerns that because of systemic risks in the financial sector, the PRC's growth slowdown may come in the form of a hard landing, rather than as a gradual

2 Felipe et al. (2013, p. 814) conclude, "Analysing [the People's Republic of] China in the year 2030, the miracle of the previous 20 years will not be, most likely, that annual growth remained at 10\%; rather, it should be that in 2010 its policymakers understood well the country's potential, together with the constraints and risks that it faced and, most importantly, that they successfully implemented a series of reforms that allowed the country to continue transforming." 
adjustment toward a slower but more sustainable and stable long-term growth rate (for an analysis of these issues, see Wray and Fernandez-Lommen 2013, and Wray and Liu 2014).

In this paper, we assess the trajectory of the PRC's potential growth rate during the last 30 years. We equate the potential growth rate of the economy with its natural growth rate. To be clear, we do not attempt to forecast the PRC's actual growth rate in the coming years which, depending on the occurrence of a variety of possible circumstances (e.g., implementation of economic policies, international shocks, etc.), could be significantly different from the growth rate consistent with the country's productive capacity. The exercise is vital in order to understand the policy dilemmas that the PRC's policymakers face. The actual growth rate of an economy has to be evaluated against the potential. This is so because, as we shall argue below, the latter sets a limit on the actual growth rate such that a persistent divergence between both has important economic implications. Our estimate of the PRC's potential growth rate for 2012, the last year in our sample, is our best estimate of the economy's potential as policymakers start discussing the 13th Five-Year Plan that will take off in 2016. Specifically, we: (i) define the PRC's potential or natural growth rate as that particular growth rate consistent with a non-increasing unemployment rate and stable inflation; (ii) investigate its determinants; (iii) delve on whether potential growth is supply or demand constrained; and (iv) design scenarios for the potential output for the 13th Five-year Plan, 2016-2020. On this last point, since we are interested in the PRC's short to medium-term growth prospects, we focus on the "growth effect" of several factors, rather than on the "level effect" on GDP (or per capita GDP). In doing so, we evaluate the relevance of various possible constraints that may limit the country's growth in the future, focusing on the effects of the slowdown in working-age population growth and on the long-term constraint imposed by the balance of payments (BOP) equilibrium. Furthermore, throughout the analysis we devote special attention to the role played by structural change, and assess the implications of the increasing importance of the services sector for the PRC's future growth.

The rest of the paper is structured as follows. Section II summarizes the discussions of the 18th Congress of the Central Committee of the Chinese Communist Party (CCP). Section III introduces and reviews the concepts of natural and BOP-constrained growth rates. Section IV discusses the estimates of both growth rates for the PRC. Section $V$ considers three scenarios for the PRC's 13th Five-Year Plan. Section VI concludes and summarizes the main results and arguments about the PRC's potential growth prospects.

\section{THE 18TH NATIONAL CONGRESS OF THE CHINESE COMMUNIST PARTY AND THE 13TH FIVE-YEAR PLAN}

From an economic policy viewpoint, a careful analysis of the decline of the PRC's growth rate is extremely important. A permanent decline in its average (potential) growth rate may be problematic for several reasons. Indeed, slower growth may hinder the PRC's process of transition from a centrallyplanned economy, in which state-owned enterprises still play a crucial role, into a market economy. The PRC's management of this transition relies on the implementation of gradual policy changes, as opposed to the "shock-therapy" measures adopted, for instance, in the Russian Federation and Eastern Europe. Together with fast growth, this gradual approach has helped make the transition trajectory smooth, so that a structural growth slowdown may raise concerns regarding the dynamics of the process.

In this context, the labor-market repercussions of a weaker growth performance are especially important, as continued job creation at a healthy rate will be necessary to ensure political stability and 
support for economic policy reforms. Rapid economic growth has long been viewed by policymakers as the most powerful antidote to reform-induced job loss. For an economy that needs about 10 million new jobs each year to keep its urban unemployment rate constant, any growth slowdown is a big deal. These questions are now coming to the fore and will inevitably need to be addressed if (or when) growth declines persistently below an annual growth rate of $7 \%-7.5 \%$, currently deemed a more appropriate growth rate by the PRC's policymakers.

It is hardly surprising, therefore, that these issues are at the center of the reform agenda approved in November 2013 by the 18th National Congress of the CCP. In the Spring of 2014, the PRC's top economic planning body gave the first steps to prepare the 13th Five-Year Plan covering 2016-2020, which will decide how to implement many of the ideas discussed in the 18th CCP.

This agenda sets out a number of bold and ambitious proposals for economic and social change to be implemented between now and 2020, aimed at assisting the PRC to gradually switch toward a more market-based economy. These reforms propose a shift to a new growth model, more focused on the quality of growth than on the quantity; more consumption-driven and less investmentdriven; and more considerate of the environment. ${ }^{3}$ The PRC's government set a target average growth rate of 7\% for the 12th Five-Year Plan (2011-2015) (Sano 2011) and we are of the view that it will keep this target for the 13th Five-Year Plan. ${ }^{4}$ Among the policy measures put forward during the 18th National Congress as essential for the country's to push forward the development agenda during the next few years, the following reforms are likely to play a key role in promoting economic efficiency:

- Increased role of markets in resource allocation. Market regulation and transparency will be improved, market forces will have a dominant role in determining prices, and the government will increasingly limit its price interventions to public services and utilities. Together with greater opening of the financial system, both for domestic and foreign agents, these measures can be expected to increase the efficiency of investment decisions and, thus, the productivity of the economy as a whole.

- Fiscal reform. Fiscal legislation is to be modernized and the tax system reformed, by clarifying roles and responsibilities, promoting budget transparency, and strengthening fiscal incentives, both at the central and local levels. These measures represent the fiscal-system complement to the evolving role of government, and aim at ensuring fiscal sustainability and stability as well as at improving fiscal efficiency and equity.

- Reform of the hukou system. The objective is to help farmers become urban residents by eliminating constraints to migration (e.g., non-portability of welfare entitlements and migrants' lack of access to basic social services) and creating appropriate incentives. This, in turn, will increase workers' mobility between rural and urban areas, and foster a more efficient allocation of labor between productive sectors.

- Open-door policy. Domestic and international mobility of productive factors, market integration, the development of new competitive advantages, and international economic cooperation will be further promoted. Moreover, entry barriers to investment will be lowered, inland areas opened up, and the development of free-trade areas further expanded. These

3 In truth, these reforms have long been talked about, but have failed to materialize for a number of reasons, the most important of which are the fear-driven precautionary saving propensity stemming from the legacy of the effects of massive layoffs and an inadequate social safety net; and the vested interests of state-owned enterprises (SOEs), especially exporters.

4 We make this statement with the information that we have at the time of writing this paper in 2014. The average target growth rates for the 10th and 11th Five-Year Plans were 7\% and 7.5\%, respectively. Shen and Luk (2014) are of the view that the PRC's potential growth rate will decline during the 13th Five-Year Plan. 
policies are intended to be key drivers of reform and economic growth, particularly by making import and export regimes more transparent; by further reducing entry barriers to foreign investment; and by increasing efficiency gains and productivity growth of domestic firms through exposing them to greater international competition.

If carried out effectively and in full, such a package of reforms is bound to have an impact not just in the short-term, but also in the long-term, potential growth rate. Moreover, these policy measures are likely to accelerate the direction of structural change of the PRC's economy toward a service economy, which may contribute to reducing the actual growth rate toward $7 \%-7.5 \%$. In turn, this will alter the relationship between growth performance and other key macroeconomic indicators with impact on the economic and social fronts, in particular:

- The proposed switch towards a more market-oriented economy will change the relationship between growth and the dynamics of employment/unemployment as well as between growth and inflation.

- The structural transformation of the economic system and the open-door policy will also affect the country's role in international markets as well as the relationship with its trading partners. The PRC's growth has been significantly bolstered by its remarkable performance as an exporter, which allowed it to run significant current account surpluses despite increasing imports (especially, in terms of primary products and raw materials). This state of affairs may also change in the future, partly as a result of the structural reforms to be undertaken, so that the role played by the current account and the BOP equilibrium as a possible long-term constraint on growth may also become critical.

For the process of structural transformation to be smooth and lead the PRC toward a stable macroeconomic path of robust and sustainable growth, these changing dynamics must be taken into account and, therefore, duly analyzed.

\section{ACTUAL, NATURAL, AND BALANCE OF PAYMENTS CONSTRAINED GROWTH RATES}

As noted earlier, Figure 1 shows the trajectories of actual and trend growth rates in the PRC over the period 1970-2012. The dynamics of the PRC's actual growth rate reflect the well-known exceptional performance over the last three decades. Except for a dip below the 5\% mark in 1989-1990, actual growth has always been above $7.5 \%$ per annum since 1982, with growth rates equal to or higher than $10 \%$ in 16 out of the 31 years to 2012.

Figure 1 also indicates that, at least from the beginning of the 1970s, the trend growth rate has been characterized by fairly regular cycles, lasting for about 10 years between troughs and about 5 years between peak and trough. When looked at in this context, the recent growth slowdown (both actual and trend growth rates) does not seem particularly worrying-indeed, it appears to be fairly in line with the previous pattern. However, this evidence is at best preliminary; an appropriate assessment of the PRC's long-term growth outlook requires a detailed analysis of its development and structural change. 
A convenient framework to investigate these issues is the estimation and assessment of the so-called natural rate of growth as the potential of the economy. ${ }^{5}$ Ultimately, an economy's productive capacity depends on the amount of labor available for employment in the production process and the average efficiency of its workers. Thus, an economy's natural growth rate can be defined as the sum of the growth rates of the labor force and labor productivity. ${ }^{6}$ At any particular point in time, actual growth can (and will) diverge from the natural growth rate, as the functioning of the economy is affected by various restrictions, rigidities, and constraints as well as by the effects of positive and negative transitory shocks. Nonetheless, actual growth cannot persistently exceed the rate consistent with full-utilization of productive resources as this would eventually result in growing inflationary pressures (and unemployment would fall). On the other hand, if actual growth were consistently lower than the potential growth rate, the resulting rising unemployment would trigger an opposite price adjustment process-decreasing wages would in due course lead to higher employment until equilibrium in the labor market is achieved. As a result, in the medium- to long-term, the economy will tend to gravitate around that particular growth rate consistent with the full-utilization of productive resources, stable inflation, and full-employment equilibrium in the labor market; that rate is the natural growth rate. Given the definition of the natural growth rate as the sum of the rate of growth of the labor force and the rate of growth of labor productivity, it follows that the measured natural rate must be that rate of growth that keeps the unemployment rate constant. Otherwise, if the actual growth rate is below the natural rate, unemployment will rise; and if the actual growth rate is above the natural rate, unemployment will fall. ${ }^{7}$

Accordingly, an investigation of the PRC's future growth trajectory and economic development should focus on exploring the dynamics of its natural growth rate, in relation to the role played by its determinants and the process of structural change that characterizes its economy.

Decades of very fast economic growth have led the PRC to soon become the world's biggest economy (in PPP terms). Fast growth has also allowed the country to narrow the gap in livingstandards with the advanced economies. However, the economic gap with the high-income countries is far from closed-even taking into account purchasing power differences via PPP calculations, its per capita GDP is still less than one-fifth that of the United States (US) and equal to about one-fourth of the Organisation for Economic Co-operation and Development (OECD) average. Meanwhile, by most other measures (education levels, health services, etc.), the PRC is still an "emerging economy" and its journey toward becoming an advanced economy is far from complete.

Two key variables that may help contextualize the PRC's process of economic development and structural transformation are: first, the rate of urbanization, which in the PRC was about $53 \%$ in 2013-this means that about 640 million people still live in the countryside; and second, the weight of the agriculture sector. The share of agricultural employment in total employment more than halved in the last 30 years,

5 This is just one possible notion of potential. There are different notions as well as methods to estimate it. See, for, example, Basu and Fernald (2009), De Masi (1997), and McMorrow and Roeger (2001). As we shall see below, here we are concerned with a short- to medium-run notion of potential output growth, consistent with policymaker's attempt to stabilize output and/or inflation at relatively high frequencies.

6 Note that the actual growth rate is the sum of employment growth and labor productivity growth. This means that actual and natural growth rates will be equal only when the labor force and employment growth rates are equal, i.e., in long-run equilibrium.

7 The definition of potential output growth we use is consistent with both New Keynesian dynamic stochastic general equilibrium models, i.e., the rate of output the economy would have if there were no nominal rigidities but all other (real) frictions remained unchanged; and with the older Keynesian notion, i.e., maximum production without inflationary pressures (Okun 1962). 
from about $82 \%$ in 1962 to $70 \%$ in 1980, and to slightly over 30\% in 2011 (Figure 3 ); ${ }^{8}$ while during the same period, the share of agricultural value added decreased drastically from about $35 \%$ to $10 \%$. However, these shares, particularly that of employment, are still considerably larger than in any advanced economy-the World Bank estimates at about 3\% the average employment share in the agriculture sector in high-income countries. In a nutshell, the PRC's 'problem' is how to get from the current share of agricultural employment to about 3\%-5\%, with industry and services providing employment at higher wages. The PRC's policymakers are very well aware that this is the key issue moving forward, as reflected in a 2013 speech by Premier Li Keqiang (Hongbin and Xiaoping 2013). ${ }^{9}$ The decline in the employment share of agriculture during 1962-2013 of about 50 percentage points corresponds to a decline of about 1 percentage point per annum. While the decline in this share during the 1960s was very slow, the reduction during the 1970s, 1980s, and 1990s increased to about 1 percentage point per annum; and it increased to about 2 percentage points per annum during the last decade. This decline in the employment share of agriculture was accompanied by very high growth rates of income per capita of at least $8 \%$ per annum, which implies that income per capita doubled every 10 years. ${ }^{10}$

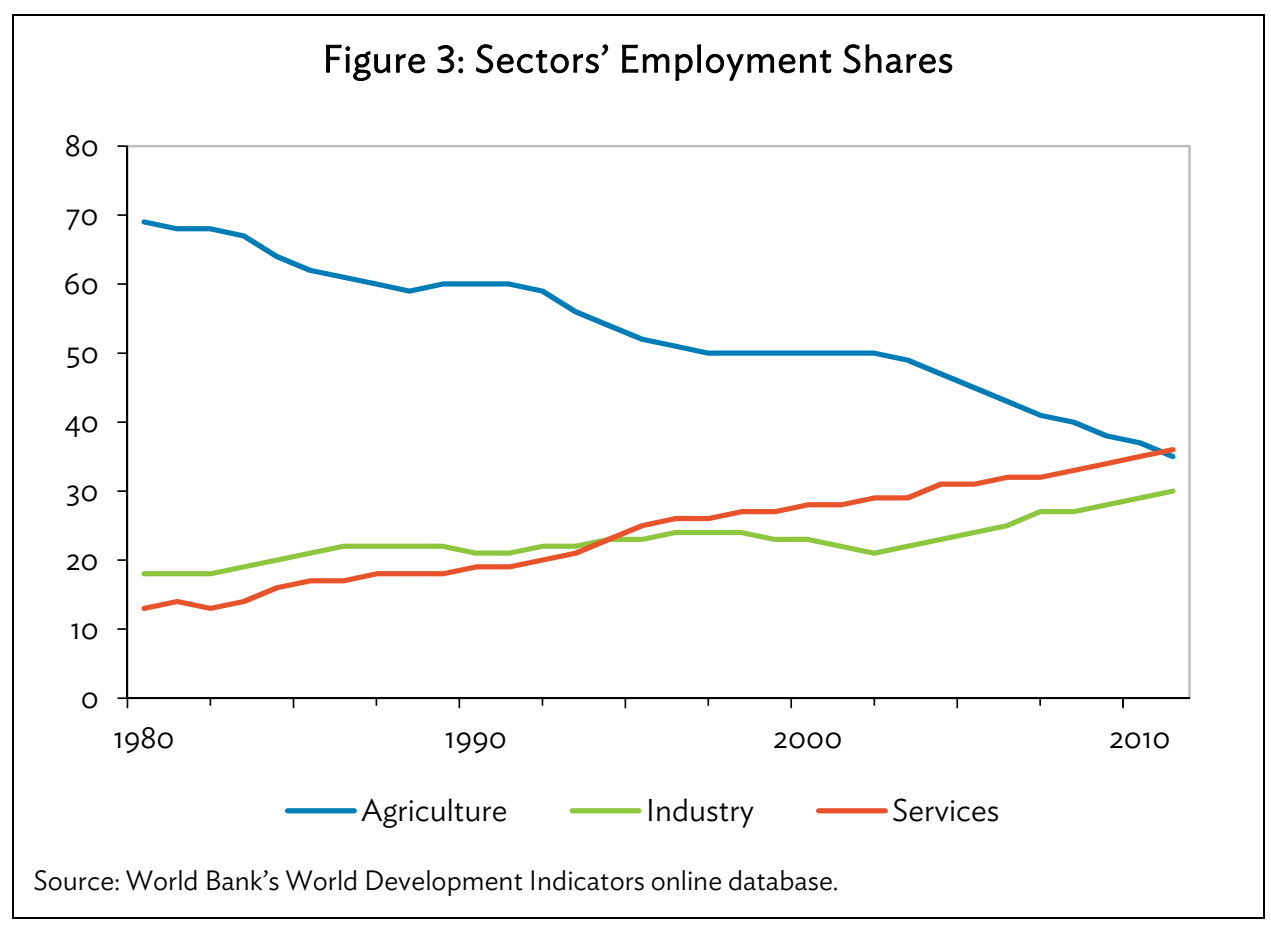

8 In 2013, the largest employer in the PRC was the services sector (38.5\%), followed by agriculture (31.4\%), and then by industry (30.1\%). During the coming decades, the share of employment in services will continue increasing and that of agriculture declining.

9 In the Premier's words, "We once increased employment by 1 million people for every per cent of GDP growth. Due to the economic restructuring in the past few years and the accelerated development of tertiary industry, every $1 \%$ of GDP growth has created 1.3 to 1.5 million job opportunities. The Ministry of Human Resources and Social Security and relevant departments calculated the statistics more than once, on my request. They said that if we are to ensure that 10 million job vacancies are created and urban registered unemployment remains at about $4 \%$, we need about 7.2\% GDP growth. We need stable growth in order to create employment" (Hongbin and Xiaoping 2013).

10 In the early 1960s, the employment share of the services sector was slightly higher than that of industry. In the late 1960 s the two shares became equal at about $9 \%$ of total employment. Between 1970 and the mid-1990s, the share of industry was higher than that of services. And since the mid-1990s, the share of employment in services has again been higher than that of industry. Today, the former is about 8 percentage points higher than the latter. 
Assuming that the PRC's structural transformation continues to drive the outflow of labor from the agriculture sector until its employment share is down to a level comparable to that of a typical advanced economy, the number of former agricultural workers who will find occupation in either the industrial or services sectors can be expected to be about 250 million. The dynamics and pattern of this labor reallocation will have a very significant impact on the country's future growth prospects.

In particular, as long as the agricultural employment share is so much larger than in the typical advanced economy, the reallocation of labor from low-productivity agricultural activities into higherproductivity employment in industry or services will increase overall aggregate productivity in the economy, and gradually will create incentives for a productivity boost in agriculture too (e.g., via mechanization). The outflow of labor from agriculture, however, is likely to increase the PRC's growth rate less than in the past. The PRC's structural transformation has already turned its trajectory from primarily industrial to a more services-based economy, and this is likely to have a negative impact on the potential growth rate, as services are generally characterized by slower labor productivity growth than industrial activities."

These considerations raise a number of questions regarding labor market dynamics, as fast growth has long been (and still is) deemed key in the PRC as the main driver of job creation. However, one may argue that in a more services-based economy, slower growth of about $7 \%-7.5 \%$ per annum may not necessarily bring about higher unemployment since many service activities are more laborintensive than industrial ones (capital-intensive). ${ }^{12}$ This is something we analyze empirically below. The PRC needs labor-intensive, not labor-saving, growth. Services are a better prescription for achieving this end than manufacturing. Moreover, economic theory predicts that, in the long run, productivity growth will depend solely on technological progress so that, independently of the sectoral allocation of productive resources, what drives technological improvements and the policy measures to accelerate them become crucial. In particular, for an emerging economy like the PRC, sustained technological progress requires both appropriate domestic policies (e.g., investment in R\&D and education) and the continued acquisition of foreign technology, for which access to advanced countries' markets remains decisive. In the case of the PRC, an additional dimension to the issue of technological advancement is related to the transition process. Specifically, the smoother the transition toward a market economy and the faster the completion of this transformation, the more likely it is that the conditions for technological catch-up and the foundations for self-sustaining technological development will be laid down appropriately.

\section{What constrains an economy's potential growth?}

As mentioned earlier, in the absence of constraints, growth will tend to the natural or potential growth rate in the long run. The equivalence between the actual and natural growth rates is consistent with macroeconomic stability which, in a growing economy, requires that output growth be such that there

1 Felipe, Kumar, and Abdon (2012) estimate a structural transformation growth model. This model leads the authors to the conclusion that the PRC's annual average growth rate between now and 2030 will decline to about $4.15 \%-5.12 \%$. This is because, in their view, it will be very difficult for the country to sustain the same pace of structural transformation during the next 2 decades, as in the previous two. See also Baumol (1967) and Baumol, Blackman, and Wolf (1985), who hypothesized that the low productivity growth in advanced nations since the mid-1970s was due to the fact that services display no relative productivity growth (he referred to them as stagnant activities). This need not be true of all services (see Maroto-Sánchez and Cuadrado-Roura 2009).

12 We need to take into account that reported unemployment in the PRC is rather low. What is significantly higher is underemployment, and this may have increased without a necessary increase in recorded unemployment. 
is equilibrium between the growth rate of productive resources (i.e., essentially, capital and labor, the so-called "supply-side" of the economy) and that of aggregate demand (i.e., the sum of aggregate consumption, public expenditure, investment, and net exports, the demand-side of the economy). Since economies are constantly affected by shocks, short-term deviations of the actual growth rate from the natural rate of growth are possible and, indeed, quite common. In the long-term, equilibrium between the two growth rates will be achieved, as the above-described adjustment mechanisms ensure that short-term deviations from equilibrium are, by definition, temporary. However, in some circumstances, the "short-term" may in fact be very "long." Indeed, the presence and incidence of supply- and/or demand-side constraints (i.e., factors that limit the growth of aggregate supply and/or demand) can prevent the economy from achieving its long-run equilibrium for lengthy periods of time.

In the case of the PRC, there are at least two factors that can potentially represent limits to faster potential growth. The first relates to the supply side of the economy, namely bottlenecks in the labor supply, due to the slowdown in working-age-population growth. The PRC still benefits from a high working-age population, but this will progressively change in the coming years as the country begins to age, possibly before transitioning into a high-income economy. Until the labor reallocation process out of agriculture is complete, we can expect that the gradual exhaustion of the demographic dividend does not pose a constraint. But in the long-term, this is bound to affect the country's potential growth (Bloom and Finlay 2009). The working-age population declined for the first time in 2011, and may continue to do so for the next 2 decades. This will have significant consequences on labor force growth, unless corrective measures that increase the labor force participation rate are adopted (e.g., extend the length of the working-age life by, for example, persuading older people to retire later, or by opening the labor market to foreign workers).

The second potential limit that must be considered when analyzing long-run growth performance relates to the role of aggregate demand and the BOP constraint. Specifically, in an open economy, a lasting lack of external demand for domestic goods and services results in imports growing consistently faster than exports. Since no country can sustain a persistent current account disequilibrium in the long-term (unless it can finance ever-growing deficits), this situation will eventually lead to unsustainable BOP problems, default, and/or a costly adjustment process via a fall in the level of economic activity. Thus, demand can significantly affect a country's growth performance even in the long run, and the balance of payments constraint can force an economy to grow below potential for prolonged periods of time. The PRC's growth has been significantly bolstered by its remarkable performance as an exporter, which allowed it to run significant current account surpluses despite increasing imports (especially, in terms of primary products and raw materials). Indeed, the PRC's remarkable growth trajectory has often been described as a textbook example of an "export-led growth process" and a likely contributing factor to its high growth rate. Most likely, the PRC's growth rate has not been BOP-constrained. This contrasts with many other emerging economies, whose growth rate is BOP- constrained. However, this state of affairs may change in the future, as a result of both domestic causes (such as the economy's structural change) and external factors, as the PRC's trading partners (in particular, the US) may try to reduce their current account deficit. Thus, the role played by current account and BOP equilibrium as a long-term constraint on growth may also become critical.

Given these considerations, to analyze the PRC's long-run growth performance, we focus on both its natural rate of growth and the so-called BOP-constrained growth rate, which is the growth rate consistent with long-run equilibrium on the current account. By considering natural and BOPconstrained growth rates jointly, our investigation takes account of the trajectory of the potential growth rate, which sets the long-run limit for actual growth as well as of the role played by supply-side 
constraints (which affect the natural rate of growth); and the (external) demand-side constraints, which can influence the BOP-constrained growth rate. From a theoretical viewpoint, the expectation is that the $\mathrm{BOP}$-constrained growth rate exceeds the natural growth rate, as growth must be consistent with BOP equilibrium in the long-term (e.g., Lanzafame, 2014). If the natural growth rate were persistently higher than the BOP-constrained growth rate, the actual growth rate would be so too, so that the demand constraint imposed by BOP equilibrium would, sooner or later, become binding. This would trigger an adjustment process that would curtail potential and actual growth, bringing them back in line with the BOP-constrained growth rate. On the contrary, if the BOP-constrained growth rate were higher than the natural rate of growth, actual growth would not be limited by demand constraints in the long run. In such a case, the supply-side constraints that can affect potential growth also determine the path of long-run growth.

Given the features of its growth process, the expectation is that the latter scenario may be the most appropriate for the PRC. In the next section, we consider the empirical evidence on this and other issues.

\section{ESTIMATES OF THE PEOPLE'S REPUBLIC OF CHINA'S NATURAL AND BALANCE OF PAYMENTS CONSTRAINED GROWTH RATES}

In this section, we present and discuss our estimates of the PRC's natural rate of growth and of the BOP-constrained growth rate, the relationship between the two rates, and the role played by the various factors that determine their dynamics. Recall that the natural growth rate was defined earlier as that rate of growth that keeps the unemployment rate constant. Also, given the definition of the BOPconstrained growth rate as the rate consistent with long-run BOP equilibrium, it is not difficult to show that the measured $\mathrm{BOP}$-constrained growth rate is given by the ratio of the growth rate of exports to the income elasticity of imports. To keep the discussion simple, we skip the technical details here. These are provided in the Appendix. We simply mention that we proceed in three steps. First, we estimate the natural and BOP-constrained growth rates using economic theory and statistical methods. Specifically, the estimates of the natural growth rate are obtained from the Kalman-filter estimation of an Aggregate Supply (AS) model..$^{13}$ As the Appendix shows, the potential or natural growth rate that we derive is the growth that keeps the unemployment rate constant and inflation equal to expected inflation. The estimation of the BOP-constrained growth model also applies the Kalman filter to the procedure suggested by Thirlwall (1979).${ }^{14}$ Second, we model the determinants of both growth rates, following the discussion in the previous section. Third, we use the estimated equation of the determinants of the natural growth rate to discuss three scenarios for the PRC's natural growth rate during the 13th Five-Year Plan, 2016-2020 (in the next section).

13 As the Appendix explains, the natural growth rate is estimated through a regression of the growth rate of GDP $\left(g_{t}\right)$ on the inflation rate $\left(\pi_{t}\right): g_{t}=\mu_{t}+\theta_{t}\left(\pi_{t}\right)+u_{t}$-equation (12) in the Appendix, where $\mu_{t}$ is the time-varying natural rate of growth.

14 As the Appendix explains, the BOP-constrained growth rate $\left(y_{B}\right)$ is calculated as the ratio of export growth $\left(x_{t}\right)$ to the income elasticity of imports $\left(\tau_{t}\right)$ (where the latter is obtained via Kalman filter estimation of a typical import function): $y_{B}=\frac{x_{t}}{\tau_{t}}-$ equation(15) in the Appendix. 
Figure 4 shows the time-varying estimates of the natural and BOP-constrained growth rates, together with the actual growth rate (Appendix Table 1 provides the data). As can be seen, actual and natural growth rates are below the BOP-constrained growth rate for most of the period, with the exception of a few occasions in the 1990s and around 2010, when the former two were slightly above the latter. This is in line with the hypothesis that the BOP-constrained growth rate sets a limit on longrun growth as well as with the view that the PRC's remarkable export performance and, consequently, its high BOP-constrained growth rate, have allowed it to grow at very fast rates for most of the period under analysis. The fact that the BOP-constrained growth rate is so high means that it did not constrain the PRC's growth. It is also worth noting that the natural growth rate has been declining since 2006, when it peaked at $11.1 \%$ (the highest potential growth rate that we estimate for 1979-2012). In 2012 it was $8.7 \%$. This decline of 2.4 percentage points in potential growth rate is smaller than that experienced by the PRC's economy during 1984-1990, from $9.8 \%$ to $6.6 \%$.

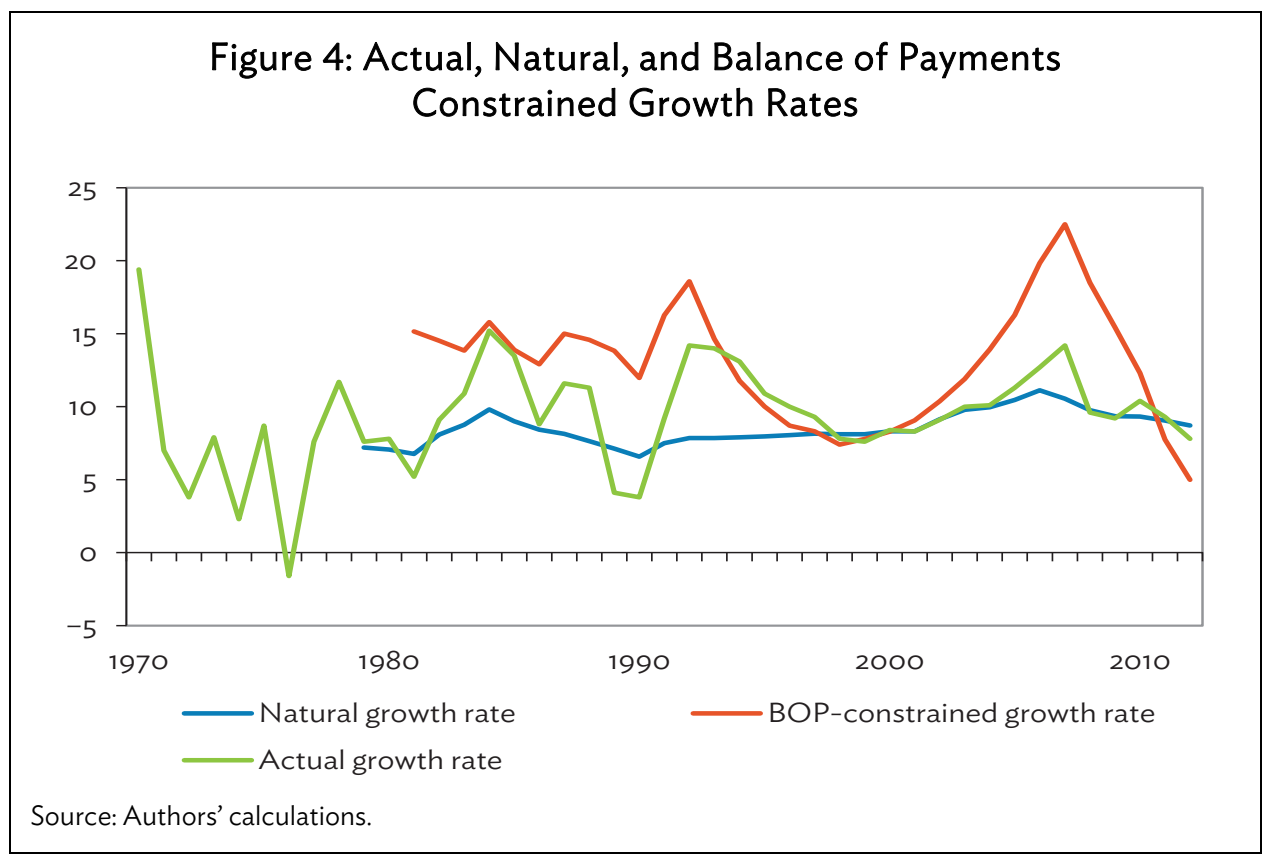

We can also note that the trajectory of the natural growth rate is more stable than that of the BOP-constrained growth rate, increasing steadily from the beginning of the 1990s up until the mid2000s, when the former started a slow decline. Since the framework we use to estimate the natural growth rate employs the inflation rate, we show this variable in Figure 5 and note that our results indicate, consistent with expectations, that when actual GDP growth is above the natural growth rate, inflation is higher than expected inflation and thus, unemployment is below the non-accelerating inflation rate of unemployment (NAIRU). As a consequence, inflation will "accelerate," that is, the change in inflation will be positive (see Figure 5 ). ${ }^{15}$

15 We have corroborated that this is indeed what occurs. 


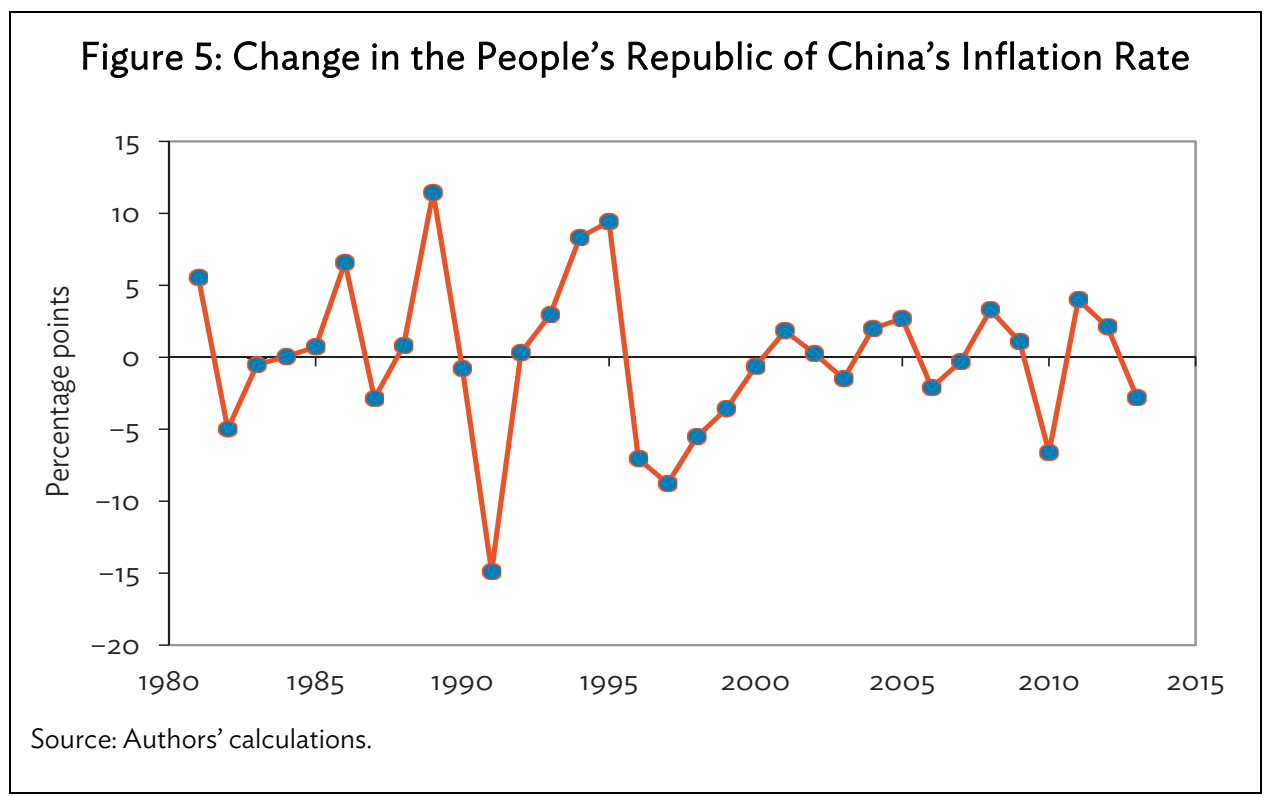

Actual and BOP-constrained growth rates also follow a downward trajectory during the second part of the 2000s. In our view, this possibly reflects the effects of the Great Recession more than a fall in potential growth due to domestic factors. Therefore, to obtain a reasonable estimate of the PRC's current potential growth rate, we smooth out these effects and give the average values for the last 5 years of both natural and BOP-constrained growth rates. The former turns out to be $9.2 \%$ and the latter $11.8 \% .^{16}$

As the natural growth rate is defined as the sum of the growth rates of labor productivity (determined by technological progress in the long run) and the labor force, both are partly exogenous and partly dependent on a number of factors. Consequently, we consider a number of variables that can influence both technological progress and labor force growth. These are the working-age population growth as a proxy for labor force growth, and the following potential determinants of technological progress and long-run labor productivity growth: a measure of the technology gap (proxied by the per capita GDP differential with respect to the US); an index of human capital (defined by total number of years of schooling); structural change; openness to international trade and outward orientation, captured through net exports over GDP; foreign direct investment over GDP; and export performance. Table 1 shows the regression estimates of the determinants of natural and BOPconstrained growth rates.

16 Note that the corresponding 5-year average trend growth rate estimated via the Corbae-Ouliaris filter (see Figure 1) is also equal to about $9.2 \%$. However, a simple visual comparison between the estimates of the trend growth rate (Figure 1) and the natural growth rate (Figure 4) shows that the latter is much less subject to cyclical ups and downs, as would be expected for long-run growth. This suggests that the estimated natural growth rate gives a better representation of the dynamics of potential growth than the trend growth rate obtained via statistical filters. 


\section{Table 1. Summary of Estimates of the Determinants of Natural and Balance of Payments Constrained Growth Rates}

\begin{tabular}{|c|c|c|c|c|c|c|c|c|}
\hline & \multicolumn{8}{|c|}{ Impact of the Determinants of the Natural Growth Rate } \\
\hline & $\begin{array}{l}\text { Change in the } \\
\text { share of } \\
\text { industrial } \\
\text { employment }\end{array}$ & $\begin{array}{l}\text { Working-age } \\
\text { population } \\
\text { growth }\end{array}$ & \multicolumn{2}{|c|}{$\begin{array}{l}\text { Share of net } \\
\text { exports in } \\
\text { GDP }\end{array}$} & $\begin{array}{c}\text { Change in the } \\
\text { share of FDI in } \\
\text { GDP }\end{array}$ & \multicolumn{2}{|c|}{$\begin{array}{c}\text { Growth rate of } \\
\text { exports }\end{array}$} & $\begin{array}{l}\text { Log of years of } \\
\text { schooling }\end{array}$ \\
\hline $\begin{array}{c}\text { Natural } \\
\text { Growth Rate }\end{array}$ & 0.53 & 0.54 & \multicolumn{2}{|c|}{0.08} & 0.31 & \multicolumn{2}{|c|}{0.02} & 3.62 \\
\hline & \multicolumn{8}{|c|}{ Impact of the Determinants of the BOP-Constrained Growth Rate } \\
\hline & $\begin{array}{l}\text { Change in the } \\
\text { share of } \\
\text { industrial } \\
\text { employment }\end{array}$ & \multicolumn{2}{|c|}{$\begin{array}{c}\text { Share of net exports in } \\
\text { GDP }\end{array}$} & \multicolumn{3}{|c|}{$\begin{array}{c}\text { Change in the share of FDI } \\
\text { in GDP }\end{array}$} & \multicolumn{2}{|c|}{$\begin{array}{c}\text { Technology GAP with the } \\
\text { US }\end{array}$} \\
\hline $\begin{array}{c}\text { BOP- } \\
\text { Constrained } \\
\text { Growth Rate }\end{array}$ & 2.45 & \multicolumn{2}{|c|}{0.63} & \multicolumn{3}{|c|}{1.37} & \multicolumn{2}{|r|}{0.47} \\
\hline
\end{tabular}

$\mathrm{BOP}=$ balance of payments, $\mathrm{FDI}=$ foreign direct investment, GDP = gross domestic product, US = United States.

Notes: Natural and BOP-constrained growth rates are in \%. The table shows the estimated coefficients, all of them statistically significant. Source: Authors' calculations.

What follows is a discussion of the results: ${ }^{17}$

\section{The Natural Rate of Growth}

a. Results indicate that the outflow of labor from the agriculture sector and, more precisely, its reallocation into the industrial sector is closely correlated with the dynamics of potential growth. Specifically, the estimates suggest that changes in the share of industrial employment affect positively the natural rate of growth: a 1 percentage point increase in the share of industrial employment leads to a 0.53 percentage point rise in the natural growth rate. ${ }^{18}$ To consider the implications of this estimate, note that during 1980-2012 the employment share in industry increased by an average of about 0.39 percentage points a year. Thus, taken at face value, our results imply that the increasing role of industry raised the PRC's potential growth rate by about 0.21 percentage points per annum.

b. The impact of the working-age population on the natural growth rate appears to be significant too; on average, every $1 \%$ growth in the working-age population has added about 0.54 percentage points to the natural rate of growth. This is in line with expectations, as the growth in the working-age population reinforced the process of fast structural change in the PRC during 1980-2012 by making abundant labor available to the fast-growing sectors of the economy. To consider the implications of

17 We stress a point made in the Introduction, namely, that we do not model and forecast actual growth. This matters because, while export growth, for example, is obviously one component of aggregate demand, our results indicate that it also raises potential growth (through the effects on productivity growth via learning-by-doing, etc., as discdussed in the text). Overall, all else constant, whether a $1 \%$ export growth leads to potential growth to further converge to or diverge from actual growth (when potential >actual), will depend on whether the effect of export growth is stronger on potential growth, or on actual growth. We do not look into this issue in the paper, as we focus on the determinants of potential growth.

18 Changes in the share of employment in services proved to be statistically insignificant. 
this estimate, note that during 1980-2012, the employment share in industry increased by an average of about 0.39 percentage points a year. As the average annual rate of growth of the working-age population was about $0.64 \%$ during the period under consideration, the yearly average impact of this variable on the natural growth rate was about 0.35 percentage points.

c. As mentioned earlier, in addition to the impact of structural change, our empirical analysis examines the role played by the process of technological catch-up undergone by the PRC. To this effect, we use a proxy for the technological gap with respect to the US. We hypothesize that the larger this gap, the wider the gains that an emerging economy, such as the PRC, can obtain via technological spillovers. ${ }^{19}$ Similarly, we consider the impact of human capital accumulation, proxied by the (logarithm of the) total number of years of schooling of the PRC's population. Moreover, they also explore the effects of trade openness and, particularly, outward orientation, proxied by the ratios of net exports and FDI over GDP as well as export performance. In addition to creating incentives for capital accumulation and a more efficient allocation of productive resources, these factors can foster technological spillovers and, particularly in the case of FDI, act as an effective vehicle for technological transfers from advanced economies. In the case of export performance, which is proxied by the growth rate of exports, the effects on labor productivity growth and technological progress have been thoroughly analyzed in the large literature on export-led growth. These effects are largely dependent on the higher growth rate achieved, thanks to faster export growth, and include: (a) the efficiency-enhancing incentives produced by competition in international markets which, to keep pace with world-leading rivals, requires domestic firms to devise new management strategies, adopt technical innovations, constantly look for ways to improve production processes, etc.; (b) the increased benefits from static economies of scale, which improve aggregate productivity by increasing productive efficiency at the firm level; (c) the development of dynamic economies of scale, which benefit aggregate productivity by fostering the intra- and inter-sector relations between firms, particularly in terms of knowhow exchange, technological spillovers, input-output linkages, and so on; and (d) the effects of so-called "learningby-doing," which refers to the improvements in labor efficiency obtained via higher specialization and faster accumulation of on-the-job experience and training induced by export-led growth.

i. While the technology gap variable turns out to be statistically insignificant, the natural rate of growth is significantly affected by human capital accumulation. Our estimate of the elasticity is 3.6 , implying that a $1 \%$ rise in the total number of years of schooling leads to a $3.6 \%$ increase in the natural growth rate. Since the total number of years of schooling increased at an average annual rate of about $0.2 \%$ during 1980-2012 and, since the average value of the natural growth rate was about $8.6 \%$ during the same period, the annual impact of human capital accumulation on the PRC's potential growth rate is about 0.06 percentage points (that is, $0.2 \times 0.036 \times 8.6=0.062$ ). This is a fairly small impact, mostly due to the

19 The technology gap is measured such that when it is equal to zero, there is no technological differential with respect to the US, and achieves a value of 100 when the technological differential is at maximum. More precisely, the technology gap is proxied by the variable $G A P=100 \times\left(1-P / P^{*}\right)$, where $P$ and $P^{*}$ are, respectively, real per capita GDP in the PRC and the US (measured in PPP terms). 
slow growth rate of human capital accumulation during the period, as measured by the growth rate of years of schooling. ${ }^{20}$

ii. Results indicate that a 1 percentage point increase in the share of net exports in GDP is associated with an increase of about $0.08 \%$ in the natural growth rate. However, as on average, the share of net exports rose by about 0.12 percentage points per annum during 1980-2012, the yearly contribution of this factor to the natural growth rate was only about 0.01 percentage points.

iii. The effect of FDI is similar; the coefficient estimate suggests that a 1 percentage point increase in the share of FDI in GDP leads to an increase of 0.31 percentage points in the natural rate of growth. Since the share of FDI grew by 0.1 percentage points a year on average, the annual contribution of this factor was about $0.03 \%{ }^{21}$

iv. The empirical evidence points to a more significant role of export growth; the estimates indicate that a 1 percentage point increase in export growth is associated with a rise of 0.02 percentage points in the natural rate of growth. Because of the remarkable export performance of the PRC, with an average annual rate of growth of nearly $16 \%$, the average yearly contribution of export growth to the natural growth rate was about 0.26 percentage points.

\section{The Balance of Payments Constrained Growth Rate}

We now turn our attention to the PRC's BOP-constrained growth rate which, as mentioned, is constructed as the ratio of (trend) export growth to the income elasticity of imports (Appendix Table 2 provides the data). Our findings reveal that, as expected, structural change has also played a substantial role in relaxing the BOP constraint on growth. See also Table 1 above:

a. Specifically, the estimates indicate that the BOP-constrained growth rate increased by about 2.45 percentage points when the share of industrial employment rose by 1 percentage point; therefore, the average annual $0.39 \%$ increase in the industrial employment share added about 0.96 percentage points a year to the BOP-constrained growth rate. This effect is not only due to the fast export growth associated to the rise of the industrial sector, but also to the positive effect that this had on the income elasticity of imports. The latter measures how quickly imports increase as a

20 It is worth noting that the average growth rate of the total number of years of schooling during 1980-2012, $0.2 \%$, is affected by several years in which the total number of years of schooling actually decreased. This is particularly the case of the Great Recession years, when the average annual growth rate of the total number of years of schooling was about $1.4 \%$. We speculate that this may reflect worse incentives for human capital accumulation, associated to lower expected returns in a slower-growing economy. It also raises concerns regarding the available data. However, if one takes a longterm view and considers data for 1950-2012, the total number of years of schooling increased by an average growth rate of about $8.5 \%$, indicating that over the longer term, the impact of human capital accumulation is likely to have been very significant indeed.

${ }^{21}$ Note that, although the quantitative importance of these factors may appear to be fairly small, the reported coefficient estimates are likely to underestimate somewhat the relevance of these determinants of productivity growth for at least two reasons: first, as mentioned, because of data limitations, the model does not include other potential determinants of productivity growth and technological progress, such as research and development (R\&D) expenditure. A more complete model would include these factors and capture the interaction between them and the variables used (i.e., technology gap, trade openness, etc. Second, the effects of technological progress may be partly captured by other variables in the model, e.g., the change in the share of industrial employment and working-age population growth. 
consequence of output growth. Together with the drivers of export performance, it is the main determinant of the BOP-constrained growth rate. Our findings indicate that both the increasing share of industrial employment and FDI had a negative impact on the PRC's income elasticity of imports, thus contributing to raising its BOP-constrained growth rate.

b. There is no evidence that changes in the share of employment in services or the growth rate of the working-age population exert a significant effect on the BOPconstrained growth rate-an outcome which, again, is consistent with expectations.

c. Contrary to the results obtained in the case of the natural growth rate estimations, the human capital proxy turns out to be a statistically insignificant determinant of the BOP-constrained growth rate. On the other hand, there is evidence of a positive impact of the technology gap, with a coefficient of 0.47 .

d. There is a (statistically) weak significant effect of the share of FDI in GDP, with a 1 percentage point rise in the latter leading to an increase of 1.37 percentage points in the BOP-constrained growth rate. As the share of FDI in GDP rose on average by about 0.1 percentage point a year during the period analyzed, this factor contributed to about $0.14 \%$ annually to the BOP-constrained growth rate.

e. Finally, the effect of trade openness is only weakly (statistically) significant too, even though the estimated effect of a 1\% change in net exports (as a share of GDP) on the $\mathrm{BOP}$-constrained growth rate is fairly strong ( 0.63 percentage points).

Summing up, the empirical evidence gathered on the determinants of the natural growth rate mirrors fairly closely the effects of the process of structural change undergone by the PRC's economy. The main drivers of the dynamics of potential growth appear to have been the growth of the workingage population (which, in turn, boosted labor force growth) and the outflow of labor from agriculture toward the industrial sector; while the share of employment in services activities does not seem to have influenced the natural growth rate. Potential growth has also benefited from the opening up of the PRC's economy to international trade and FDI. The main route through which the increasing prominence of industry has bolstered the natural growth rate has been the associated growth of exports. The latter factor has also played the main role in determining the country's remarkably high $\mathrm{BOP}$-constrained growth rate, which has also been bolstered by the beneficial effects of structural change and FDI on the income elasticity of imports.

\section{SCENARIOS FOR THE PEOPLE'S REPUBLIC OF CHINA'S POTENTIAL GROWTH DURING THE 13TH FIVE-YEAR PLAN, 2016-2020}

We now consider three scenarios for the path of the PRC's natural growth rate during 2016-2020. To do this, we use the model of the potential growth rate discussed in the previous section (Table 1). Figure 6 graphs the estimated natural growth rate series obtained via Kalman-filter estimation, and the one predicted by our model, discussed in the previous section. As can be seen, the predicted series does a good job tracking the actual natural growth rate (Appendix Table 3 provides the data). 


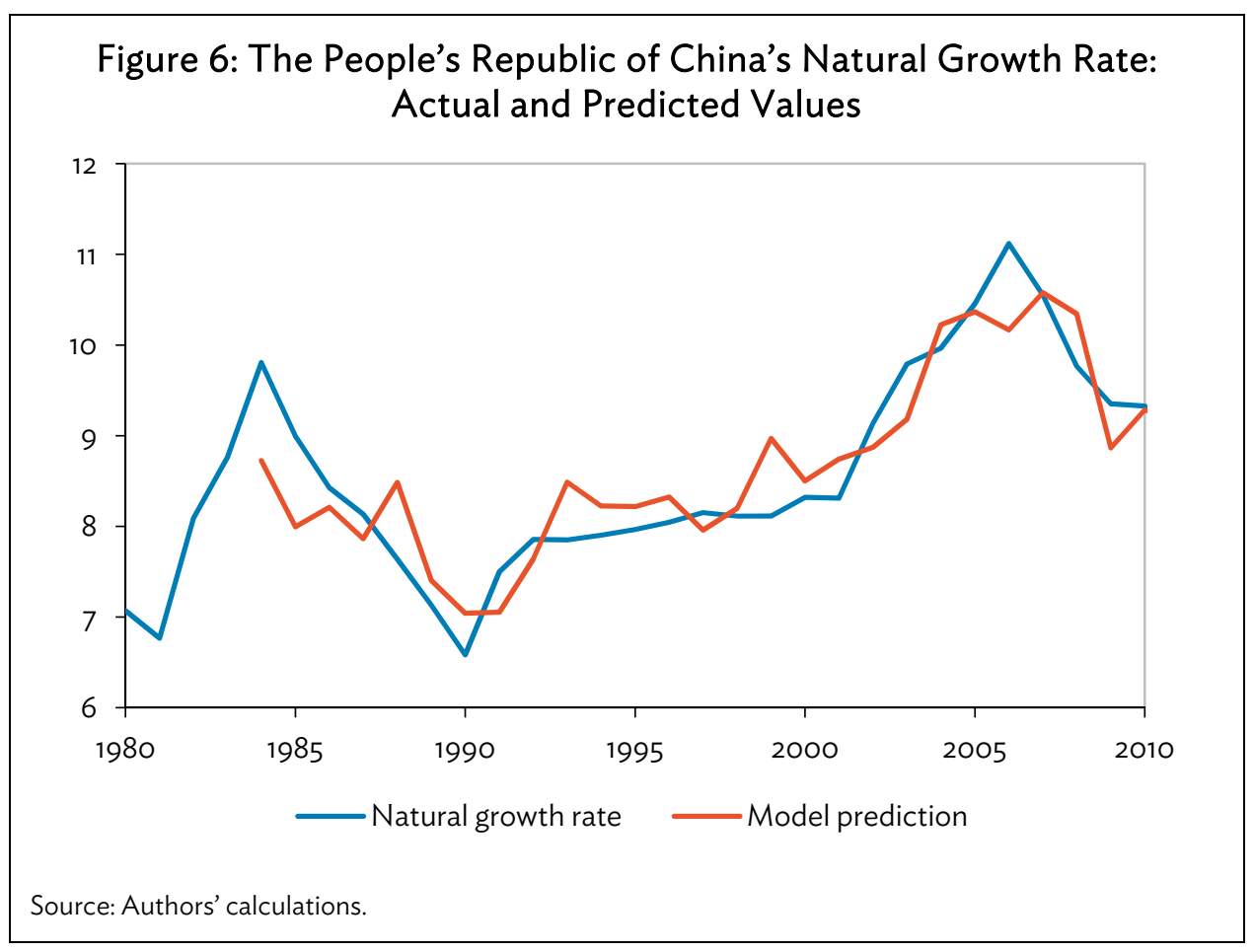

We use the coefficient estimates in Table 1 to construct three possible scenarios, shown in Table 2. In the first one, the effects of the Great Recession are assumed to be temporary, so that the annual growth rate of exports returns to values in line with those seen during the 2 decades up to the second half of the 2000s, $18 \%$, the average growth rate of exports during 1990-2006. Similarly, taking as reference the average values for 1990-2006, the annual changes in the shares of net exports and FDI in GDP are both positive ( 0.5 and 0.2 percentage points, respectively); and so is the growth rate of the total number of years of schooling, $2 \%$. Further, we assume that structural change proceeds at a slow pace, so that the share of industrial employment still increases during the period, by 0.5 percentage points each year. Finally, based on projections from the United Nations, the annual growth rate of the working-age population is assumed to be negative and equal to $-0.1 \%$ (we use this estimate in all three scenarios in Table 2).

Under this setup, the natural growth rate returns to about $10.4 \%$. In such a case, an actual growth rate of 7\%-7.5\% (currently seen as optimal by policymakers in the PRC) would bring about increasing unemployment. In different circumstances, this situation would likely lead to the implementation of short-term policy measures to increase aggregate demand and GDP growth to keep pace with potential growth and, thus, keep unemployment from increasing. However, this situation would be problematic for the PRC's authorities if their objective is to attain an actual growth rate of about $7 \%-7.5 \%$. 
Table 2. Scenarios for the Path of the People's Republic of China's Natural Growth Rate, 2016-2020

\begin{tabular}{|c|c|c|c|c|c|c|c|}
\hline & $\begin{array}{l}\text { Share of } \\
\text { Industrial } \\
\text { Employment }\end{array}$ & $\begin{array}{l}\text { Working- } \\
\text { Age } \\
\text { Population } \\
\text { Growth }\end{array}$ & $\begin{array}{l}\text { Share of } \\
\text { Net } \\
\text { Exports in } \\
\text { GDP }\end{array}$ & $\begin{array}{l}\text { Share of } \\
\text { FDI in GDP }\end{array}$ & $\begin{array}{l}\text { Growth } \\
\text { Rate of } \\
\text { Exports }\end{array}$ & $\begin{array}{l}\text { Years of } \\
\text { Schooling }\end{array}$ & $\begin{array}{c}\text { Natural } \\
\text { Growth } \\
\text { Rate }\end{array}$ \\
\hline & \multicolumn{6}{|c|}{ First Scenario: The effects of the Great Recession are temporary } & \\
\hline Coefficient & 0.53 & 0.54 & 0.08 & 0.31 & 0.02 & 3.62 & \\
\hline 5-year average change & 0.50 & -0.10 & 0.50 & 0.20 & 18.00 & 2.00 & 10.4 \\
\hline \multirow[t]{2}{*}{ 5-year impact } & 0.27 & -0.05 & 0.04 & 0.06 & 0.36 & 0.65 & \\
\hline & \multicolumn{6}{|c|}{ Second Scenario: The effects of the Great Recession are permanent } & \\
\hline Coefficient & 0.53 & 0.54 & 0.08 & 0.31 & 0.02 & 3.62 & \\
\hline 5-year average change & -1.50 & -0.10 & -2.50 & -1.50 & 0.00 & -1.50 & 7.0 \\
\hline \multirow[t]{2}{*}{ 5-year impact } & -0.80 & -0.05 & -0.20 & -0.47 & 0.00 & -0.49 & \\
\hline & \multicolumn{6}{|c|}{ Third Scenario: Transformation toward a services economy } & \\
\hline Coefficient & 0.53 & 0.54 & 0.08 & 0.31 & 0.02 & 3.62 & \\
\hline 5-year average change & -1.50 & -0.10 & -0.10 & -0.50 & 5.00 & -1.00 & 7.8 \\
\hline 5-year impact & -0.80 & -0.05 & -0.01 & -0.16 & 0.10 & -0.33 & \\
\hline
\end{tabular}

$\mathrm{FDI}=$ foreign direct investment, GDP = gross domestic product.

Source: Authors' calculations.

The second scenario assumes that the effects of the Great Recession are permanent. As in the previous scenario, we assume the acceleration of the structural transformation of the economy toward services and a decline in the weight of industry. In addition, in this setup, we assume that the effects of the Great Recession are persistent and larger than in the first scenario. The share of industrial employment decreases by an average of 1.5 percentage points per year, but the annual growth rate of exports is now assumed to be $0 \%$ during the period of analysis. This results in a more negative annual change in the GDP shares of net exports ( -2.5 percentage points) and FDI ( -1.5 percentage points). The annual growth rate of years of schooling is also negative and equal to $-1.5 \%$, as in a slowly growing economy, the return to human capital accumulation decreases. In this case, an actual growth rate of $7.5 \%$ would be higher than the natural growth rate, which declines to about $7 \%$. This situation would lead to decreasing unemployment with inflationary pressures.

The third scenario is an attempt to isolate the effects of structural change and, in particular, of a possible acceleration in the process of transformation of the PRC into a services-based economy. As such, the main variation with respect to the first scenario is that the share of industrial employment decreases by an average of 1.5 percentage points per year. A decreasing role for industry in this scenario implies a slowdown in export growth (5\%) and a negative annual change in the share of net exports (-0.1 percentage points), while in a less dynamic export-driven growth process, the change in the GDP share of FDI turns negative too ( -0.5 percentage points). The annual growth rate of years of schooling is negative and equal to $-1 \%$, in line with that during 2007-2012. As can be seen, the outcome of the acceleration of the structural transformation toward a service economy is that potential growth slows down to about $7.8 \%$. This growth rate is broadly in line with the current pace of 
GDP growth, so that in this scenario, the unemployment rate would be broadly stable if policymakers in the PRC are successful in delivering the currently targeted 7\%-7.5\% GDP growth.

\section{CONCLUSIONS: THE PEOPLE'S REPUBLIC OF CHINA'S POTENTIAL GROWTH PROSPECTS DURING THE 13TH FIVE-YEAR PLAN AND IMPLICATIONS FOR POLICY}

The CCP set an ambitious agenda for the 12th Five-Year Plan (2011-2015). As discussed at the 18th National Congress in 2013, reforms are expected to continue during the 13th Five-Year Plan (20162020). The PRC needs to change its growth model into one that is less capital and energy-intensive, and less dependent on credit and real estate booms; yet it needs to continue achieving high growth rates to generate employment in industry and services during the coming decades so as to absorb 240 million agricultural workers, about $31 \%$ of total employment, and largely surplus labor. ${ }^{22}$ During the last few years, the actual growth rate has declined significantly, hence, policymakers wonder whether this decline is temporary or permanent, whether the economy's potential has been affected or not, and whether the capacity of the economy to create employment has been affected.

This paper provides a discussion of the PRC's potential or natural growth rate, defined as the rate consistent with the full utilization of productive resources (i.e., constant unemployment rate) and stable inflation (i.e., actual inflation equals the expected inflation rate). First, we have calculated the natural growth rate for the period 1979-2012 as well as the BOP growth rate, and established that only the former is binding in the PRC. Second, we have modeled their determinants. Third, we have discussed three possible scenarios for the 13th Five-Year Plan 2016-2020. The analysis we have developed has some important economic policy implications and allows us to make a series of conclusions regarding the PRC's future growth prospects:

1. Our results indicate that in 2012, the PRC's potential growth rate was $8.7 \%, 2.4$ percentage points below the 2006 peak, 11.1\%. This finding is consistent with other estimates (e.g., IMF 2014). Smoothing out the effects of the Great Recession by considering a 5-year average up to 2012, our findings indicate that the natural growth rate is still $9.2 \%$, about the same as the average actual growth rate for the period. Based on our empirical work, this can be considered the best estimate of the PRC's natural or potential growth rate as the PRC's policymakers initiate discussions for the 13th Five-Year Plan. Since the natural growth rate is the growth rate that keeps the unemployment rate constant (and stable inflation), this natural rate implies that the $7 \%$ growth rate target of the 12th Five-Year Plan, possibly also the same target for the 13th Five-Year Plan, may, in fact, not be sufficient to prevent unemployment from rising in the long run. This conclusion, however, is subject to a number of caveats that we discuss below.

2. The recent decline in potential growth rate may be due to the impact of the Great Recession, particularly, via its negative effects on exports. If the recent global recession does not leave permanent scars on both the world and the PRC's economies, the slowdown in potential growth may be only temporary. Under our first scenario, the PRC's potential growth rate may return to over $10 \%$. If this scenario materializes but the actual growth rate stays at about $7 \%-$ $7.5 \%$, then there will be further upward pressures on the unemployment rate.

22 An analysis of agriculture's employment share indicates that assuming an increase in income per capita of $6.5 \%$ per annum, the share will decline to about $24 \%$ by 2020 , that is, 7 percentage points below what it was in 2013; and that it will further decline to about 18\% by 2025 (Felipe, Dacuycuy, and Lanzafame 2014). 
3. Under a second scenario, the Great Recession may have permanent effects on the PRC's economy, in which case, the country's potential growth rate may even decrease to below the actual rate. This situation would lead to decreasing unemployment with inflationary pressures.

4. The PRC is increasingly becoming a services-based economy, and our estimation results indicate that the structural transformation of its economy will possibly lead to a reduction in the natural growth rate during the 13th Five-Year Plan. In our third scenario, consistent with this setting, the natural growth rate declines and approaches the actual desired rate of 7\%$7.5 \%$. In this case, the unemployment rate will not increase. We believe this second trend will dominate in the medium- to long-term that we are concerned with.

5. We believe that the PRC's potential growth rate will decline during the next few years as the economy becomes more service-oriented. Policymaking in the PRC could be guided by our second scenario, where potential declines to the actual rate. This way, policymakers would be able to deal with both unemployment and inflation pressures. The decline in the natural rate will come about through the direct effect on aggregate productivity, due to lower productivity growth in the services sector as well as through the indirect effect on export growth, which the evidence suggests is the real engine of the PRC's potential growth. Specifically, a declining industrial sector vis-à-vis services activities is likely to reduce the role played by manufacturing exports in fostering productivity growth. This development is considered by many an essential part of the rebalancing process to be undergone by the PRC's economy, which should gradually switch from an export- and investment-driven growth model to one characterized by a growing role of domestic demand and, particularly, private consumption. Such an adjustment process is certainly desirable, particularly because of its beneficial effects on the long-term sustainability of the PRC's growth. However, it also opens up several policy questions, the most significant of which are undoubtedly related to the mechanisms through which productivity growth can be enhanced in the services sector. Furthermore, as mentioned above, since service activities are more labor-intensive than industrial ones, the same aggregate growth rate in a more services-based economy will generally give rise to a faster rate of job creation. Thus, at least in terms of its effects on the labor market, a slowdown in the PRC's natural growth rate may not necessarily be a concern. In addition, however slower the pace of productivity growth of services vis-à-vis that of industry, the gap with low-productivity agricultural activities means that the constant outflow of labor out of the latter sector is likely to continue benefiting potential growth, even if most farmers will find new occupations in services rather than in industry. This suggests that appropriate internal migration policies and, in particular, an effective reform of the hukou system, can increase the PRC's potential growth, at least until the outflow of labor from agriculture is over.

6. Among the other economic policy reforms outlined by the 18th CCP National Congress, the measures aimed at increasing the country's openness to trade and FDI, and in general, the outward orientation of the economy, are likely to play a crucial role in the country's future growth performance. The empirical evidence supports the view that the PRC's remarkable growth performance can be rightly described as export-led. Thus, if effective in fostering FDI and export growth, the proposed intensification and expansion of the "open-door policy" may bring about substantial benefits.

7. The reform agenda should also take into account the possible supply- and/or demand-side constraints on potential growth. In particular, given the significant role played by the workingage population growth in reinforcing potential growth during 1980-2012, we can expect that 
the exhaustion of the demographic dividend will exert a negative effect on the PRC's future growth performance. As mentioned above, to some extent, these effects may be reduced through the implementation of corrective measures aimed at increasing the labor force participation (e.g., to extend the length of the working-age life). Results also indicate that the natural rate of growth is positively affected by human capital accumulation (measured by the growth rate of years of schooling), although, since this effect is slow and takes place over a long period, its overall impact is small.

8. With respect to the long-term constraint imposed by the BOP equilibrium, our analysis indicates, as expected, that this was not binding during the period under analysis - the estimated BOP-constrained growth rate is above the natural growth rate for most of the period, with the exception of a few years in the 1990s and during 2010-2012. As mentioned, this recent decline is likely to depend on the effects of the Great Recession, but it does show that the benefits accruing to the PRC's economy from international trade should not be considered as permanent - the determinants of the BOP-constrained growth rate should, thus, be thoroughly studied. In this respect, the main empirical finding is that the increasing share of industrial employment has had a significantly positive impact on the BOP-constrained growth rate during 1980-2012. This appears to have worked not only by promoting export growth, but also via the income elasticity of imports, a measure of how quickly imports increase as a consequence of output growth. Specifically, the increase in the share of industrial employment was associated with a reduction in the value of the income elasticity of imports. In turn, together with the PRC's remarkable export performance, this has relaxed the BOP constraint on GDP growth. However, we find that the share of employment in the services sector is not significant. Thus, as observed for the natural rate of growth, we can expect the structural transformation toward an increasingly services-based economy to reduce the country's BOPconstrained growth rate. Meanwhile, the evidence points to a significantly positive impact of FDI (expressed as a percentage of GDP) on the BOP-constrained growth rate. As discussed earlier, the share of FDI in GDP reflects the degree of technological transfer; but it also reflects the economy's openness to international investors. Thus, this finding reinforces the support for the "open-door policy."

Summing up, our analysis of the PRC's potential growth rate outlines a challenging economic scenario for its policymakers. The PRC's remarkable growth performance during the last 40 years represents an exception and there is little doubt that, in due course, growth will decline toward values consistent with the world economy's average growth rate-a phenomenon that economists refer to as "regression to the mean" in growth (Pritchett and Summers 2014). The finding that the natural growth rate is still about $9 \%$ represents our best estimate of its current value. We agree with the view that it will decline in the future. The central question is whether the PRC's growth slowdown will come in the form of a smooth decline toward a slower, but sustainable, growth rate, or as a hard landing. To investigate this issue, a thorough analysis of potential growth in the PRC is critical, as the likelihood of a sudden (rather than gradual) deterioration of long-term growth performance is closely related to the deviations of actual from potential growth. In fact, because of the various mechanisms linking the rate of productivity growth and technological progress to the pace of economic growth, potential growth is likely to be endogenous with respect to the actual growth rate, at least to a certain extent. In this sense, the recent slowdown in economic growth resulting from the negative effects on the global economy of the Great Recession, may turn out to have persistent effects on the PRC's natural growth rate-a potential threat we refer to in various parts of the paper. 
22 | ADB Economics Working Paper Series No. 418

Finally, there are clear opportunities for economic policy to decrease the likelihood of this potential scenario, and this way facilitate a smooth transition toward a more sustainable growth model. This should be done by removing the obstacles that impede a more efficient allocation of productive resources and which limit the PRC's potential growth. 


\section{APPENDIX: ESTIMATION OF NATURAL AND BALANCE OF PAYMENTS CONSTRAINED GROWTH RATES}

\section{Estimation of the natural rate of growth}

As noted in footnote 7 in Section III in the text, the definition of potential output growth we use is consistent with both New Keynesian dynamic stochastic general equilibrium models, i.e., the rate of output the economy would have if there were no nominal rigidities but all other (real) frictions remained unchanged; and with the older Keynesian notion, i.e., maximum production without inflationary pressures (Okun 1962).

To estimate the natural rate of growth $\left(g^{N}\right)$, we adopt a revised version of the methodology put forward by León-Ledesma and Thirlwall (2002). Their approach is based on a standard formalization of Okun's Law in growth-rate form that measures the natural rate of growth as that particular growth rate that is consistent with a non-changing unemployment rate, that is:

$$
\Delta U_{t}=\xi-\gamma g_{t}
$$

where $g_{t}$ is the growth rate of GDP and $\Delta U_{t}$ is the change in the unemployment rate. The natural growth rate is therefore given by $g^{N}=\frac{\xi}{\gamma}$. Using this result we can express (1) as:

$$
\Delta U_{t}=-\gamma\left(g_{t}-g^{N}\right)
$$

To avoid the possible bias that may arise due to the effects of labor hoarding, León-Ledesma and Thirlwall (2002) rely on the inverse of Okun's Law as formalized in (1), that is:

$$
g_{t}=\omega-\delta\left(\Delta U_{t}\right)+\varepsilon_{t}
$$

where $\varepsilon_{t}$ is the error term. The estimate of the growth rate that is consistent with an unchanging unemployment rate is therefore:

$$
g^{N}=\omega
$$

The coefficients in Okun's model are not pure structural parameters. Rather, they are reduced form, or semi-reduced form, parameters that incorporate several fundamental structural parameters representative of the macroeconomic behavior and of the characteristics of the adjustment mechanisms that lie behind the inverse relationship between output and unemployment gaps over the business cycle. $\delta=1 / \gamma$, where $\gamma$ is Okun's coefficient in equation (1), is an important indicator of the degree of interdependence of output and labor movements around their long-run paths and is regarded as a benchmark for policymakers to measure the cost of high unemployment.

We modify the León-Ledesma and Thirlwall methodology in two ways. First, we do not assume that the natural growth rate is constant, and instead estimate it as a (possibly) time-varying rate of growth. Second, rather than estimating Okun's Law, we rely on the relationship between inflation and 
GDP growth as formalized in standard macroeconomic theory to estimate the natural growth rate via an Aggregate Supply (AS) model in growth rates, with output growth on the left-hand side and CPI inflation on the right-hand side. The reason is that the PRC's unemployment data does not include the substantial underemployment that exists in the PRC and hence make estimates of Okun's Law problematic. Therefore, and more precisely, we estimate the natural rate of growth as that particular growth rate that is consistent with inflation being equal to expected inflation (i.e., stable inflation). Moreover, as we show below, our method is also consistent with the definition of the natural growth rate, that is, that growth rate consistent with a non-changing unemployment rate.

We start with a standard AS model that relates the price level to the output gap. In log-levels, this AS model can be written as:

$$
\ln P_{t}=\ln P_{t}^{e}+\beta\left(\ln Y_{t}-\ln Y_{t}^{N}\right)
$$

where the log price level $\left(\ln P_{t}\right)$ depends on the log of the expected price level $\left(\ln P_{t}^{e}\right)$ and on the difference between the actual $\left(\ln Y_{t}\right)$ and the natural $\left(\ln Y_{t}^{N}\right)$ GDP levels (i.e., the output gap). Now we take the first difference of (5) and obtain:

$$
\ln P_{t}-\ln P_{t-1}=\left(\ln P_{t}^{e}-\ln P_{t-1}^{e}\right)+\beta\left(\ln Y_{t}-\ln Y_{t-1}\right)-\beta\left(\ln Y_{t}^{N}-\ln Y_{t-1}^{N}\right) .
$$

Note that this expression relates the inflation rate $\left(\ln P_{t}-\ln P_{t-1}=\pi_{t}\right)$ to the expected inflation rate $\left(\ln P_{t}^{e}-\ln P_{t-1}^{e}=\pi_{t}^{e}\right)$ and to the growth rates in actual $\left(\ln Y_{t}-\ln Y_{t-1}=g_{t}\right)$ and potential $\left(\ln Y_{t}^{N}-\ln Y_{t-1}^{N}=g_{t}^{N}\right)$ output. Thus, it can be formalized as:

$$
\pi_{t}=\pi_{t}^{e}+\beta\left(g_{t}-g_{t}^{N}\right)
$$

Expression (7) shows that inflation will be higher (lower) than expected inflation whenever actual growth is higher (lower) than the natural growth rate. If agents have rational expectations, then the actual inflation rate will be equal to the expected inflation rate in the long-term, so that $g_{t}=g_{t}^{N}$. Thus, to close the model, we adopt a simple form of rational expectations and assume the following specification for the expected rate of inflation:

$$
\pi_{t}^{e}=\alpha_{t} \pi_{t}+v_{t}
$$

where $v_{t}$ is a random shock and $\alpha_{t}$ is a time-varying parameter reflecting the public's degree of accuracy in forecasting the inflation rate. Rational expectations imply that in the long-term, agents do not make systematic errors in forecasting inflation, so that $\pi_{t}^{e}=\pi_{t}$ and $\alpha_{t}=1$, which implies that $g_{t}=g_{t}^{N}$. However, because of several possible reasons (e.g., incomplete information, imperfect knowledge of the inflation process, lagged reaction to inflation news, etc.), in the short-term, the value of $\alpha_{t}$ can be different from 1 , so that $\pi_{t}^{e} \neq \pi_{t}$ and $g_{t} \neq g_{t}^{N}$. 
To see the implications of this argument formally, substitute (8) into (7) and (abstracting from the error term) rearrange the resulting expression as follows:

$$
\left(g_{t}-g_{t}^{N}\right)=\left(\frac{1-\alpha_{t}}{\beta}\right) \pi_{t}
$$

As in the long-term $\alpha_{t}=1$, equation (8) implies that $\pi_{t}^{e}=\pi_{t}$ (since $E\left[v_{t}\right]=0$ ); and equation (9) implies that $\left(g_{t}-g_{t}^{N}\right)=0$. In the short-term, there can be deviations from this equilibrium: if $\alpha_{t}>1$, equation (9) indicates that, given the actual inflation rate $\left(\pi_{t}\right), g_{t}<g_{t}^{N}$, that is, the actual growth rate is lower than the natural growth rate. Equation (7) shows that this is so because expected inflation is higher than actual inflation, i.e. $\pi_{t}^{e}>\pi_{t}$. In the opposite case when $\alpha_{t}$ is lower than its long-term value (i.e., $\alpha_{t}<1$ ), we have $\pi_{t}^{e}<\pi_{t}$ and $g_{t}>g_{t}^{N}$.

The evolution of $\alpha_{t}$ over time will depend on agents' learning process regarding inflation forecasts. Rational agents will tend to correct forecasting errors over time, so that one way to model changes in $\alpha_{t}$ is to assume that they are some function of inflation-forecast errors, that is:

$$
\Delta \alpha_{t}=\psi\left(\pi_{t}-\pi_{t}^{e}\right) \quad \text { with } \psi>0
$$

According to (10), when inflation is equal to expected inflation, $\alpha_{t}$ does not change and remains equal to 1 . Thus, when $\pi_{t}^{e}=\pi_{t}$ (and $g_{t}=g_{t}^{N}$ ) we also have a stable inflation rate (i.e., actual inflation rate equals the expected rate), barring random inflation shocks-inflation does not "accelerate" because the unemployment rate is equal to the NAIRU, so that $\Delta U_{t}=0$. Out of equilibrium, if $\left(\pi_{t}-\pi_{t}^{e}\right)>0$ then $\alpha_{t}$ will tend to increase toward 1 ; and if $\left(\pi_{t}-\pi_{t}^{e}\right)<0$ then $\alpha_{t}$ will tend to decrease toward 1.

Turning again to our approach to estimate of the natural growth rate, rearranging (9) and adding the error term $u_{t}$ we obtain

$$
g_{t}=g_{t}^{N}+\frac{\left(1-\alpha_{t}\right)}{\beta} \pi_{t}+u_{t}
$$

Expression (11) formalizes the relationship between output growth and inflation in a model with time-varying parameters, which can be more generally specified as

$$
g_{t}=\mu_{t}+\theta_{t}\left(\pi_{t}\right)+u_{t}
$$

so that $g_{t}^{N}=\mu_{t}$ and $\frac{\left(1-\alpha_{t}\right)}{\beta}=\theta_{t}$. Models such as (12) can be estimated via the Kalman filter, a recursive procedure whereby the estimate of a parameter is updated sequentially as new information becomes available. It allows us to obtain regression coefficients $\mu_{t}$ and $\theta_{t}$ that may change with time. 
Operationally, the Kalman filter requires that the model be written in state-space form, that is, as measurement and transition equations. The measurement equation is (12) while the transition equations are $\mu_{t}=\mu_{t-1}+\varepsilon_{t}$ and $\theta_{t}=\theta_{t-1}+\xi_{t}$; with $\hat{\mu}_{0}=\mu_{0}+\rho_{0}$ and $\hat{\theta}_{0}=\theta_{0}+\varphi_{0}$ as prior estimates. $u, \varepsilon$, $\xi, \rho$ and $\varphi$ are random errors, assumed independent of each other. ${ }^{23}$ Starting from the initial values $\hat{\mu}_{0}$ and $\hat{\theta}_{0}$, the problem is how to use the sequential information $g_{t}$ in order to form an optimal sequence of updated predictions of $\mu_{t}$ and $\theta_{t}$ and their associated variance matrices. In a nutshell, this is done by generating a series of one-step-ahead prediction errors, which contain unknown parameters, estimated via maximum likelihood. To obtain time series for the transition variables, we apply the Kalman Smoothing procedure, which uses all the information in the sample to provide smoothed estimates. This procedure differs from simple Kalman filtering, as the latter technique uses only the information available up to the beginning of the estimation period. Smoothed series tend to produce more gradual changes than the filtered ones and, as discussed by Sims (2001), they provide more precise estimates of the actual time variation in the data.

Our method is entirely consistent with the definition of the natural growth rate in Okun's Law, i.e., that particular growth rate associated with a non-changing unemployment rate. The reason is that, since the natural growth rate is equal to the sum of the growth rates of labor productivity and of the labor force, unemployment will rise whenever the actual rate of growth falls below the natural growth rate; while it will fall in the opposite case. Standard macroeconomic theory and, in particular, the expectations-augmented Phillips curve indicate that, in the long-term, unemployment will be equal to the NAIRU, therefore:

$$
\Delta U_{t}=0 \text {, as } U_{t}=U_{t-1}=N A I R U \text { and } g_{t}=g_{t}^{N} .
$$

By definition, when the unemployment rate is equal to the NAIRU, actual inflation is equal to the expected inflation rate $\left(\pi^{E}\right)$, so that:

$$
\pi_{t}=\pi^{E} \text {, as } \Delta U_{t}=0 \text { and } g_{t}=g_{t}^{N} \text {. }
$$

In the short-term, Okun's Law indicates that whenever growth is faster (slower) than the natural rate of growth, the unemployment rate will fall (rise) and the expectations-augmented Phillips curve implies that inflation will be higher (lower) than expected inflation. In the long run, growth is equal to the natural rate of growth, which is that particular growth rate consistent with an unchanging unemployment rate (equal to the NAIRU), and with inflation being constant and equal to expected inflation. As such, the natural rate of growth can be estimated via the León-Ledesma and Thirlwall approach, as formalized in (1) or (3) as well as via the AS-type model expressed in (11) and (12).

\section{Estimation of the balance of payments constrained growth}

Following Thirlwall (1979), the BOP-constrained growth rate is derived under the assumption that countries need to achieve equilibrium in the balance of payments. It is, therefore, the growth rate that is consistent with long-run BOP equilibrium. Lack of external demand for a country's domestic goods and services will trigger an increase in imports not matched by an equal growth rate of exports, with the

23 The time-varying parameters are assumed to evolve as unit roots to capture possible level breaks or trend patterns. This is a standard procedure in the literature in state-space modeling (e.g., Harvey 1989). 
consequence that the country will incur a deficit. Since countries cannot sustain permanent deficits (unless they can be financed), the BOP-constrained growth rate can impose a ceiling on the growth rate.

The BOP-constrained growth rate $\left(y_{B}\right)$ is given by the ratio of export growth $\left(x_{t}\right)$ to the income elasticity of imports $\left(\tau_{t}\right)$ (where the latter is obtained via Kalman-filter estimation of a typical import function):

$$
y_{B}=\frac{x_{t}}{\tau_{t}}
$$

To avoid the incidence of cyclical fluctuations on the time-varying estimates of the BOPconstrained growth rate (obtained via the Kalman filter), the growth rates of imports and exports were filtered using the Corbae and Ouliaris filter (Corbae, Ouliaris, and Philips 2002; Corbae and Ouliaris 2006). 
28 Appendix. Estimation of Natural and Balance of Payments Constrained Growth Rates

Appendix Table 1: Natural, Balance of Payments Constrained, and Actual Growth Rates, the People's Republic of China

(\%)

\begin{tabular}{|c|c|c|c|}
\hline Year & $\begin{array}{c}\text { Natural Growth } \\
\text { Rate }\end{array}$ & $\begin{array}{c}\text { BOP-Constrained } \\
\text { Growth Rate }\end{array}$ & $\begin{array}{c}\text { Actual Growth } \\
\text { Rate }\end{array}$ \\
\hline 1970 & & & 19.4 \\
\hline 1971 & & & 7.0 \\
\hline 1972 & & & 3.8 \\
\hline 1973 & & & 7.9 \\
\hline 1974 & & & 2.3 \\
\hline 1975 & & & 8.7 \\
\hline 1976 & & & -1.6 \\
\hline 1977 & & & 7.6 \\
\hline 1978 & & & 11.7 \\
\hline 1979 & 7.2 & & 7.6 \\
\hline 1980 & 7.1 & & 7.8 \\
\hline 1981 & 6.8 & 15.2 & 5.2 \\
\hline 1982 & 8.1 & 14.5 & 9.1 \\
\hline 1983 & 8.8 & 13.8 & 10.9 \\
\hline 1984 & 9.8 & 15.8 & 15.2 \\
\hline 1985 & 9.0 & 13.9 & 13.5 \\
\hline 1986 & 8.4 & 12.9 & 8.8 \\
\hline 1987 & 8.1 & 15.0 & 11.6 \\
\hline 1988 & 7.6 & 14.6 & 11.3 \\
\hline 1989 & 7.1 & 13.8 & 4.1 \\
\hline 1990 & 6.6 & 12.0 & 3.8 \\
\hline 1991 & 7.5 & 16.3 & 9.2 \\
\hline 1992 & 7.9 & 18.6 & 14.2 \\
\hline 1993 & 7.9 & 14.6 & 14.0 \\
\hline 1994 & 7.9 & 11.8 & 13.1 \\
\hline 1995 & 8.0 & 10.0 & 10.9 \\
\hline 1996 & 8.0 & 8.7 & 10.0 \\
\hline 1997 & 8.2 & 8.3 & 9.3 \\
\hline 1998 & 8.1 & 7.4 & 7.8 \\
\hline 1999 & 8.1 & 7.8 & 7.6 \\
\hline 2000 & 8.3 & 8.3 & 8.4 \\
\hline 2001 & 8.3 & 9.1 & 8.3 \\
\hline 2002 & 9.1 & 10.4 & 9.1 \\
\hline 2003 & 9.8 & 11.9 & 10.0 \\
\hline
\end{tabular}

continued on next page 
Appendix Table 1 continued

\begin{tabular}{|c|c|c|c|}
\hline Year & $\begin{array}{c}\text { Natural Growth } \\
\text { Rate }\end{array}$ & $\begin{array}{c}\text { BOP-Constrained } \\
\text { Growth Rate }\end{array}$ & $\begin{array}{c}\text { Actual Growth } \\
\text { Rate }\end{array}$ \\
\hline 2004 & 10.0 & 13.9 & 10.1 \\
\hline 2005 & 10.5 & 16.3 & 11.3 \\
\hline 2006 & 11.1 & 19.8 & 12.7 \\
\hline 2007 & 10.6 & 22.5 & 14.2 \\
\hline 2008 & 9.8 & 18.5 & 9.6 \\
\hline 2009 & 9.4 & 15.4 & 9.2 \\
\hline 2010 & 9.3 & 12.3 & 10.4 \\
\hline 2011 & 9.0 & 7.8 & 9.3 \\
\hline 2012 & 8.7 & 5.0 & 7.8 \\
\hline
\end{tabular}

$\mathrm{BOP}=$ balance of payments.

Source: Authors' calculations.

Appendix Table 2: Balance of Payments Constrained Growth Rate, Income Elasticity of Imports, and Trend Growth Rate of Exports

\begin{tabular}{|c|c|c|c|}
\hline Year & $\begin{array}{c}\text { BOP-Constrained } \\
\text { Growth Rate }\end{array}$ & $\begin{array}{c}\text { Income Elasticity of } \\
\text { Imports }\end{array}$ & $\begin{array}{c}\text { Trend Growth } \\
\text { Rate of Exports }\end{array}$ \\
\hline 1980 & & 0.9 & 14.2 \\
\hline 1981 & 15.2 & 0.9 & 13.1 \\
\hline 1982 & 14.5 & 0.9 & 12.7 \\
\hline 1983 & 13.8 & 0.9 & 13.0 \\
\hline 1984 & 15.8 & 0.8 & 13.7 \\
\hline 1985 & 13.9 & 1.0 & 14.6 \\
\hline 1986 & 12.9 & 1.1 & 15.4 \\
\hline 1987 & 15.0 & 1.0 & 15.9 \\
\hline 1988 & 14.6 & 1.1 & 16.1 \\
\hline 1989 & 13.8 & 1.2 & 15.7 \\
\hline 1990 & 12.0 & 1.3 & 15.0 \\
\hline 1991 & 16.3 & 0.9 & 14.1 \\
\hline 1992 & 18.6 & 0.8 & 13.1 \\
\hline 1993 & 14.6 & 0.9 & 12.3 \\
\hline 1994 & 11.8 & 1.0 & 11.9 \\
\hline 1995 & 10.0 & 1.2 & 12.1 \\
\hline 1996 & 8.7 & 1.4 & 13.0 \\
\hline 1997 & 8.3 & 1.6 & 14.5 \\
\hline 1998 & 7.4 & 2.0 & 16.7 \\
\hline 1999 & 7.8 & 2.1 & \\
\hline 2000 & 8.3 & 2.3 & \\
\hline & & & \\
\hline
\end{tabular}


30 | Appendix. Estimation of Natural and Balance of Payments Constrained Growth Rates

Appendix Table 2 continued

\begin{tabular}{|c|c|c|c|}
\hline Year & $\begin{array}{c}\text { BOP-Constrained } \\
\text { Growth Rate }\end{array}$ & $\begin{array}{c}\text { Income Elasticity of } \\
\text { Imports }\end{array}$ & $\begin{array}{c}\text { Trend Growth } \\
\text { Rate of Exports }\end{array}$ \\
\hline 2001 & 9.1 & 2.3 & 21.0 \\
\hline 2002 & 10.4 & 2.2 & 23.0 \\
\hline 2003 & 11.9 & 2.0 & 24.3 \\
\hline 2004 & 13.9 & 1.8 & 24.9 \\
\hline 2005 & 16.3 & 1.5 & 24.5 \\
\hline 2006 & 19.8 & 1.2 & 23.1 \\
\hline 2007 & 22.5 & 0.9 & 20.8 \\
\hline 2008 & 18.5 & 1.0 & 17.9 \\
\hline 2009 & 15.4 & 0.9 & 14.6 \\
\hline 2010 & 12.3 & 0.9 & 11.2 \\
\hline 2011 & 7.8 & 1.0 & 8.1 \\
\hline 2012 & 5.0 & 1.1 & 5.5 \\
\hline
\end{tabular}

$\mathrm{BOP}=$ balance of payments.

Notes: BOP-constrained growth rate and trend growth rate of exports are in \%. Trend growth rate of exports is obtained via the Corbae and Ouliaris filter.

Source: Authors' calculations.

\section{Appendix Table 3: Natural and Predicted Growth Rates}

(\%)

\begin{tabular}{|c|c|c|}
\hline Year & $\begin{array}{c}\text { Natural } \\
\text { Growth Rate }\end{array}$ & $\begin{array}{c}\text { Predicted } \\
\text { Natural } \\
\text { Growth Rate }\end{array}$ \\
\hline 1979 & 7.2 & - \\
\hline 1980 & 7.1 & - \\
\hline 1981 & 6.8 & - \\
\hline 1982 & 8.1 & - \\
\hline 1983 & 8.8 & - \\
\hline 1984 & 9.8 & 8.7 \\
\hline 1985 & 9.0 & 8.0 \\
\hline 1986 & 8.4 & 8.2 \\
\hline 1987 & 8.1 & 7.9 \\
\hline 1988 & 7.6 & 8.5 \\
\hline 1989 & 7.1 & 7.4 \\
\hline 1990 & 6.6 & 7.0 \\
\hline 1991 & 7.5 & 7.1 \\
\hline 1992 & 7.9 & 7.6 \\
\hline 1993 & 7.9 & 8.5 \\
\hline 1994 & 7.9 & 8.2 \\
\hline 1995 & 8.0 & 8.2 \\
\hline
\end{tabular}


Appendix Table 3 continued

\begin{tabular}{|c|c|c|}
\hline Year & $\begin{array}{c}\text { Natural } \\
\text { Growth Rate }\end{array}$ & $\begin{array}{c}\text { Predicted } \\
\text { Natural } \\
\text { Growth Rate }\end{array}$ \\
\hline 1996 & 8.0 & 8.3 \\
\hline 1997 & 8.2 & 8.0 \\
\hline 1998 & 8.1 & 8.2 \\
\hline 1999 & 8.1 & 9.0 \\
\hline 2000 & 8.3 & 8.5 \\
\hline 2001 & 8.3 & 8.7 \\
\hline 2002 & 9.1 & 8.9 \\
\hline 2003 & 9.8 & 9.2 \\
\hline 2004 & 10.0 & 10.2 \\
\hline 2005 & 10.5 & 10.4 \\
\hline 2006 & 11.1 & 10.2 \\
\hline 2007 & 10.6 & 10.6 \\
\hline 2008 & 9.8 & 10.3 \\
\hline 2009 & 9.4 & 8.9 \\
\hline 2010 & 9.3 & 9.3 \\
\hline 2011 & 9.0 & 9.2 \\
\hline 2012 & 8.7 & 9.0 \\
\hline
\end{tabular}




\section{REFERENCES*}

Anand, R., K. C. Cheng, S. Rehman, and L. Zhang. 2014. Potential Growth in Emerging Asia. IMF Working Paper. No. 14/2. January.

Basu, S. and J. G. Fernald. 2009. What Do We Know (and not Know) About Potential Output? Federal Reserve Bank of St. Louis Review. (July/August). pp. 187-213.

Baumol, W. 1967. Macroeconomics of Unbalanced Growth: The Anatomy of Urban Crises. American Economic Review. 57 (3). pp. 415-425.

Baumol, W., S. Blackman, and E. Wolf. 1985. Unbalanced Growth Revisited: Asymptotic Stagnancy and New Evidence. American Economic Review. 75 (4). pp. 806-817.

Bloom, D. E. and J. E. Finlay. 2009. Demographic Change and Economic Growth in Asia. Asian Economic Policy Review. 4 (1). pp. 45-64.

Corbae, D. and S. Ouliaris. 2006. Extracting Cycles from Non stationary Data. In D. Corbae, S. N. Durlauf, and B. E. Hansen, eds. Econometric Theory and Practice: Frontiers of Analysis and Applied Research. New York: Cambridge University Press.

Corbae, D., S. Ouliaris, and P. C. B. Phillips. 2002. Band Spectral Regression with Trending-Data. Econometrica. 70 (3). pp. 1067-1109.

De Masi, P. R. 1997. IMF Estimates of Potential Output: Theory and Practice. IMF Working Paper. No. 97/177. December.

Eichengreen, B., D. Park, and K. Shin. 2013. Growth Slowdowns Redux: New Evidence on the MiddleIncome Trap. National Bureau of Economic Research Working Paper. No. 18673. January.

Felipe, J., C. Dacuycuy, and M. Lanzafame. 2014. The Declining Share of Agricultural Employment in the People's Republic of China: How Fast? ADB Economics Working Paper Series. No. 419. Manila: Asian Development Bank.

Felipe, J., U. Kumar, and A. Abdon. 2012. Using Capabilities to Project Growth 2010-2030. Journal of the Japanese and International Economies. 26 (1) (March). pp. 153-166.

Felipe, J., U. Kumar, N. Usui, and A. Abdon. 2013. Why Has China Succeeded? And Why it Will Continue to Do so. Cambridge Journal of Economics. 37 (4) (July). pp. 791-818.

Harvey, A. 1989. Forecasting, Structural Time Series Models and the Kalman Filter. Cambridge University Press.

Hongbin, Q. and M. Xiaoping. 2013. From the Horse's Mouth. HSBC Global Research (15 November). Full Transcript of Premier Li Keqiang's speech delivered at the 16th National Congress of the All-China Federation of Trade Unions.

* ADB recognizes China as the People's Republic of China. 
International Monetary Fund (IMF). 2014. People's Republic of China, Article IV Consultation. IMF Country Report. No. 14/235. International Monetary Fund.

Lanzafame, M. 2014. The Balance of Payments Constrained Growth Rate and the Natural Rate of Growth: New empirical evidence. Cambridge Journal of Economics. 38 (4). pp. 817-838.

León-Ledesma, M. and A.P. Thirlwall. 2002. The Endogeneity of the Natural Rate of Growth. Cambridge Journal of Economics. 26 (4). pp. 441-459.

Maroto-Sánchez, A. and J. Cuadrado-Roura. 2009. Is Growth of Services an Obstacle to Productivity Growth? A Comparative Analysis. Structural Change and Economic Dynamics. 20 (4). pp. 254265.

McMorrow, K. and W. Roeger. 2001. Potential Output: Measurement Methods, "New" Economy Influences and Scenarios for 2001-2010 -A Comparison of the EU15 and the US-. Directorate-General for Economic and Financial Affairs (ECFIN). European Commission.

Okun, A. M. 1962. Potential GNP: Its Measurement and Significance. Cowles Foundation Paper 190. New Haven, CT: Cowles Foundation.

Perkins, D. H. 2013. East Asian Development. Foundations and Strategies. Cambridge, MA, and London, England: Harvard University Press.

Pritchett, L. and L. Summers. 2014. Asiaphoria Meets Regression to the Mean. NBER Working Paper 20573. National Bureau of Economic Research.

Sano, J. 2011. Key Targets in the 12th Five-Year Plan and Policies for their Realization -Reasons for the 7\% Growth Target. Pacific Business and Industries. 11 (42). pp. 2-20.

Shen, J. and M. Luk. 2014. A Proposal to Cut 2015 GDP Target to 6.7\%. Mizhuo Economics Update. 14 October 2014.

Sims, C. 2001. Comments on Sargent and Cogley's Evolving Post World War II US Inflation Dynamics. NBER Macroeconomics Annual. 16. pp. 373-379.

Thirlwall, A. P. 1979. The Balance of Payments Constraint as an Explanation of International Growth Rate Differences. Banca Nazionale del Lavoro Quarterly Review. 32 (128). pp. 45-53.

Wray, R and Y. Fernandez-Lommen. 2013. Monetary and Fiscal Operations in the People's Republic of China: An Alternative View of the Options Available. ADB Economics Working Paper. No. 380. October.

Wray, R. and X. Liu 2014. Options for China in a Dollar Standard World. Levy Economics Institute Working Paper. No. 783. January. 


\section{The People's Republic of China's Potential Growth Rate The Long-Run Constraints}

We estimate the People's Republic of China's (PRC's) potential growth rate in 2012 at $8.7 \%$, and at $9.2 \%$ for the average of 2008-2012, about the same as the average actual growth rate for this period. This rate is the natural growth rate, that is, the rate consistent with a constant unemployment rate and stable inflation. The PRC's natural growth rate displays a downward trend since 2006, when it peaked at 11.1\%.

\section{About the Asian Development Bank}

ADB's vision is an Asia and Pacific region free of poverty. Its mission is to help its developing member countries reduce poverty and improve the quality of life of their people. Despite the region's many successes, it remains home to approximately two-thirds of the world's poor: 1.6 billion people who live on less than $\$ 2$ a day, with 733 million struggling on less than $\$ 1.25$ a day. ADB is committed to reducing poverty through inclusive economic growth, environmentally sustainable growth, and regional integration.

Based in Manila, ADB is owned by 67 members, including 48 from the region. Its main instruments for helping its developing member countries are policy dialogue, loans, equity investments, guarantees, grants, and technical assistance. 